\title{
النشر الإلكتروني للمخطوطات العربية: محاولة لوضع دليل عمل استرشادي
}

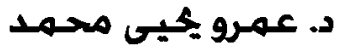 \\ اختصياصي رقمنة التراث المخطوط \\ مركزتوثيق التراث الحضـاري والطبيعي - مكتبة الإسكندرية \\ amr.yehia1@gmail.com
}

مستخلص:

هذه الدراسة محاولة لوضع دليل عمل استرشادي مقترح للنشر الإلكتروني للمخطوطات العربية، وتأتي أهمية هذا الدليل كونه أداة تنفيذية تساعد الباحثين والمتخصصين على تنفيذ عمليات النشر الإلكتروني للمخطوطات العربية. كما تعود أهمية هذا الدليل إلى العناصر التي اعتمد عليها الباحث في بنائه، والمتمثلة في: الخبرات المهنية لمتخصصي المخطوطات العربية بمختلف فروعها، ومجهودات الإنتاج العلمي في هذا الاتجاه، فضاًلا عن الاستعانة بمجمموعة من اعنمات أدلة العمل الاسترشادية المعنية برقمنة أوعية المعلومات التراثية ونشرها إلكترونيَّا. كما يتكون هذا الدليل من عدة مراحل، والتي تمثلت في مجموعة من المراحل المتتالية والمتمثلة في: المرحلة التمهيدياة، ومرحلة جمع ورصد محتوى المخطوطات العربية. ثم مرحلة الخطوات الخاصة بإعدادات النشر الإلكتروني للمخطوطات العربية، ثم مرحلة الإجراءات الخاصية بكيفية وصول المستفيدين لموقع المخطوطات العربية من خلال شبكة الإنترنت، وذلك لمساعدة المستخدمين

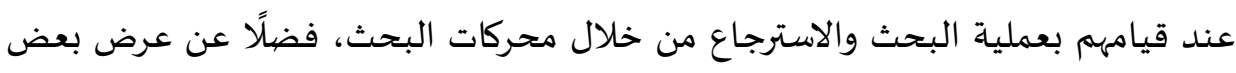
النقاط التي تشير إلى كيفية الاستفادة من التسـويق الإلكتروني لمحتوى المخطوطات العربية المنشور إلكترونيًّا. وأخيرًا المرحلة الختامياة.

الكلمات المفتاحية: النشر الإلكتروني، المخطوطات العربية؛ النشر الإلكتروني للمخطوطات

$$
\text { العربية؛ تكنولوجيا المعلومات والمخطوطات العربية }
$$


1. تمهيد:

التوعية بالتراثي العربي والتعريف بجهود الحضارة العربية إنجازاتها وما خلفه الأسلاف من تراث عريق من أهم المؤكدات على الهوية العربية (الحفيان، 2016)، وبالتالي فإن هذا التهرئ التراث

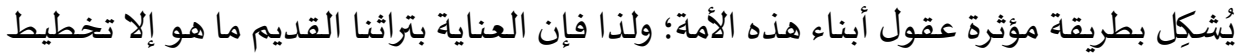

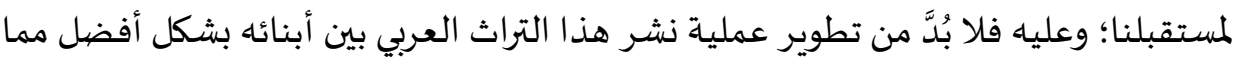

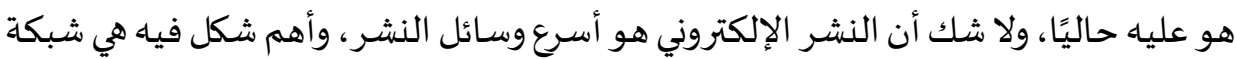

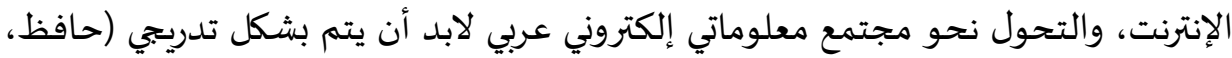

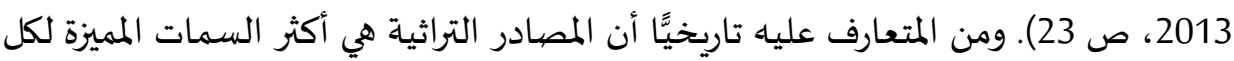

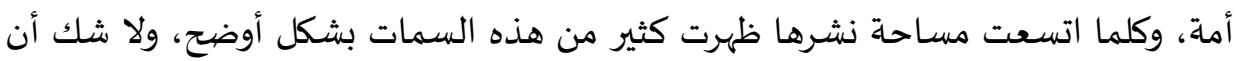
المخطوطات العربية أحد أهم أشكال هذه المصادر؛ لأهها تستمد أهميتها من كونها مصديدرًا تراثيَّا

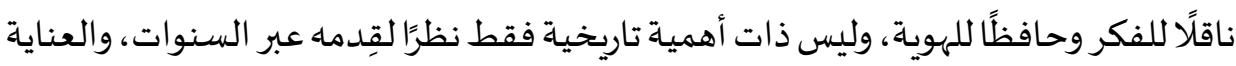
والحفاظ علهها لا يعني وضعها في مخازن مغلقة بل يعني حفظها في العقول؛ وعلياء تظهر أهمية

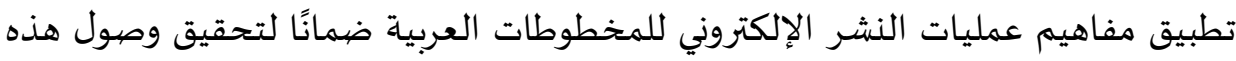

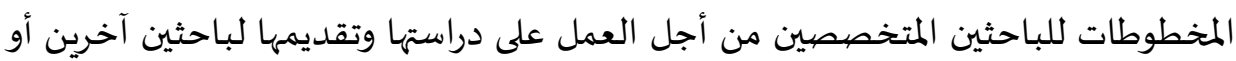

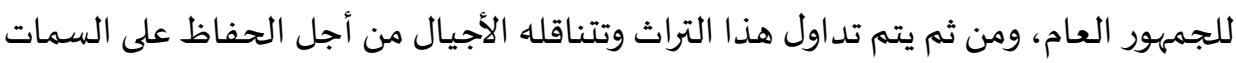
المميزة للأمة العربية.

$$
\text { 2. مصطلحات الدراسة: }
$$

يُعرِفِ معجم مصطلحات المكتبات والمعلومات - على شبكة الإنترنت - المخطوط على أنه كتابة أي نوع من النصوص (نص علمي، نوتة موسيقية، خريطة، إلخ) مكتوب بخط

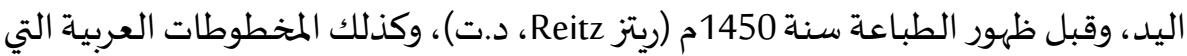
استمرت بعد هذا التاريخ وتدخل تحت مظلة التراث العربي سواء كانت هذه الكتابات بخط المؤلف نفسـا أو الناسخ أو نسخة منقولة عن النسخة الأصلية. كما يُعرّف المعجم الوسيط المخطوط على أنه الكتاب المكتوب بخط اليد (المعجم

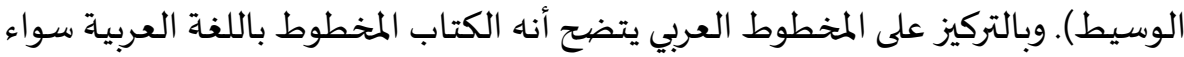


أكان في شكل لفائف أو في شكل صحف ضُم بعضها إلى بعض إلى هيئة دفاتر أو كراريس.

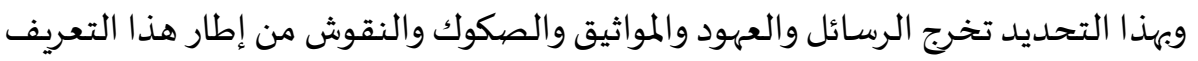

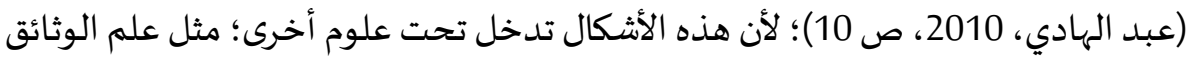

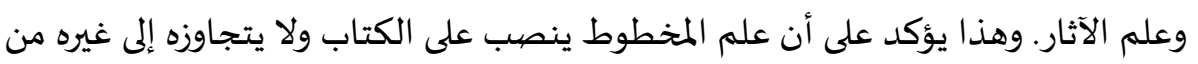

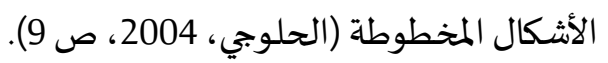
ب. ب النشر الإلكتروني: يُعرِفِ معجم مصطلحات المكتبات والمعلومات - على شبكة الإنترنت - أن عملية

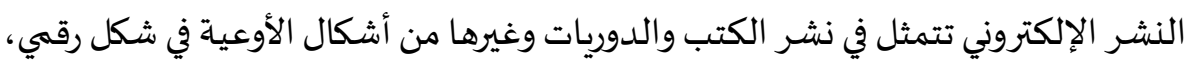
وعادة ما تكون على وسيط إلكتروني مثل الـ CD-ROM أو عبر شبكة الإنترنت مباشرة؛ ليُّتاح للمستخدمين سواء بمقابل مادي أو بدون عن طريق الموردين المتخصصيصين.

\section{ج. مراحل النشر الإلكتروني:}

تتقارب وجهات نظر مجموعة من خبراء مجال المكتبات وعلم المعلومات فيما يخص

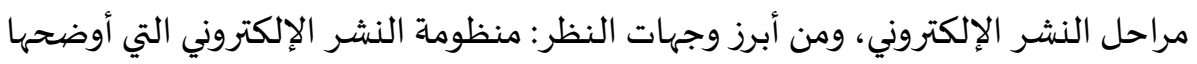

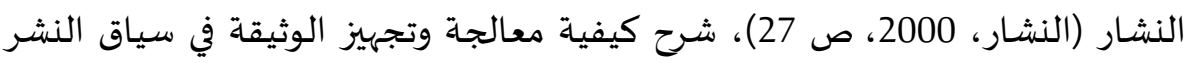

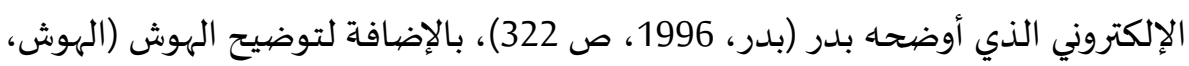

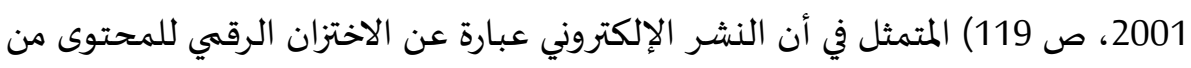

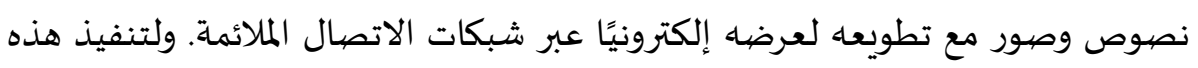

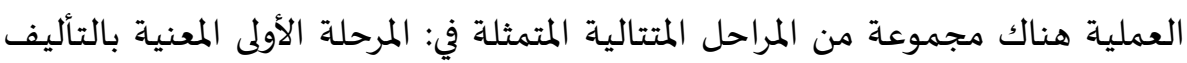

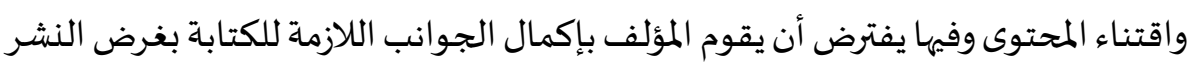

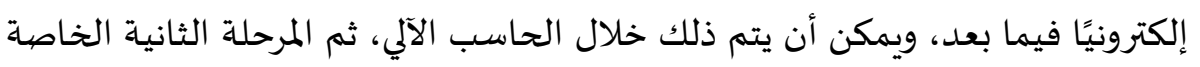

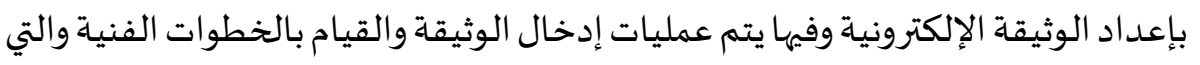

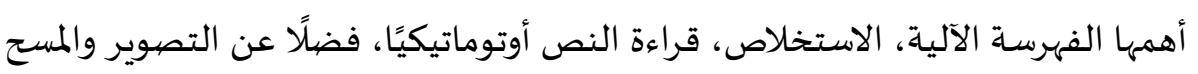

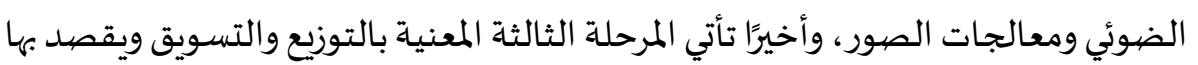
توصيل الرسالة الفكرية إلي المستفيدين. 


\section{د. النشر الإلكتروني للمخطوطات العربية:}

مما سبق يحاول الباحث وضع تعريف إجرائي لعملية النشر الإلكتروني للمخطوطات

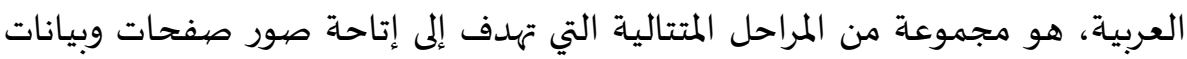

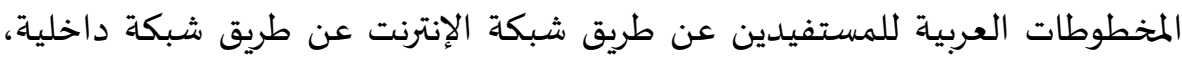

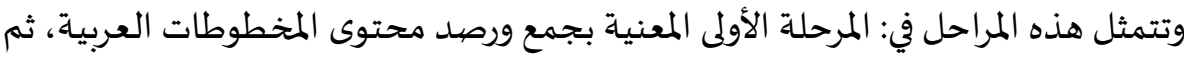

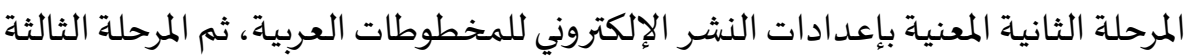
المعنية بالوصول لمحتوى المخطوطات العربية.

3.

أ. أحدود الموضيوعية:

تقوم الدراسـة على رصد مراحل النشر الإلكتروني للمخطوطات العربية؛ مما أدى

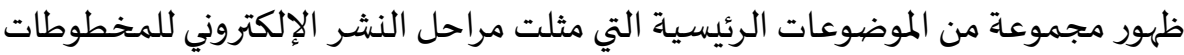

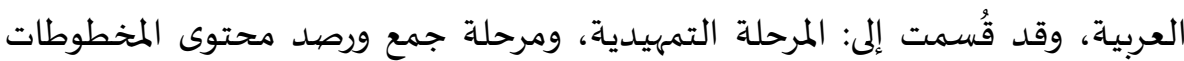

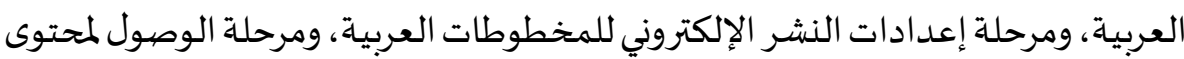
المخطوطات العربية، وأخيرًا المرحلة الختامية.

ب. الحدود اللغوية: حاولت الدراسة استخدام دراسات الإنتاج الفكري والمعايير المنشورة باللغتين العربية والإنجليزية.

ج. الحدود الشكلية: حاولت الدراسة استخدام وتوظيف عدة اشكال لأوعية المعلومات، والتي تمثلت في: مقالات الدوريات، والأطروحات الجامعية، وبحوث مؤتمرات، والكتُب لبناء هذا الدليل.

\section{د. الحدود الزمنية:}

استخدمت الدراسـة تجارب النشر الإلكتروني للمخطوطات العبية والإنتاج الفكري

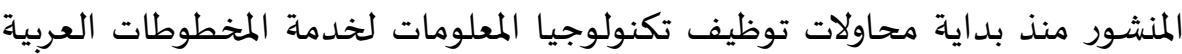
لنشرها إلكترونيًا، وبدء ذلك في عام 1992م، وتتبعت الدراسة هذا الإنتاج الفكري حتى عام 
استعانت الدراسة بتجارب النشر الإلكتروني للمخطوطات العربية وبالإنتاج الفكري المنشورين على شبكة الإنترنت من خلال محركات البحث، وقواعد البيانات المتاحة.

$$
\text { 4. مصيادر حصر مفردات الدراسـة: }
$$

أ. قواعد البيانات على شبكة الإنترنت:

رجع الباحث إلى بنك المعرفة المصري (بنك المعرفة المصري، د.ت)، ومن أكثر المصادر

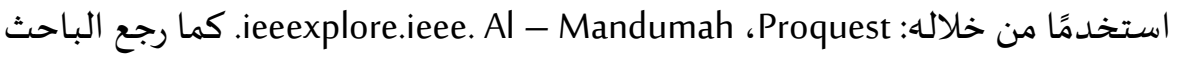
إلى مجموعة من قواعد بيانات الوصول الحر Open Access، وكانت أكثر المصيادر استخدامًا:

Academia (Academia, n.d), Researchgate (Researchgate, 2008), Cybrarians Journal (Cybrarians Journal, 2005), Algerian scientific journal platform (Algerian scientific journal platform, n.d).

\section{ب. الأدلة الببليوجرافية:}

التراث المخطوط: ببليوجرافية الإنتاج الفكري العربي من 1882 إلى 2008 (عبد الهادي،

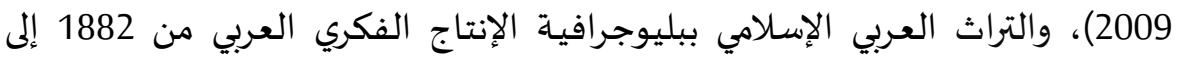

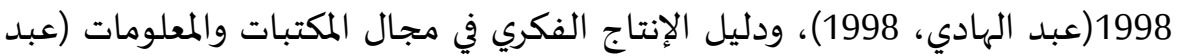

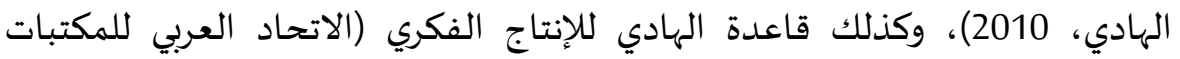

$$
\text { والمعلومات(اعلم)، 2013). }
$$

5.

بناءً على ما سبق يرجح الباحث أن أهمية هذا الدليل المقترح تكمن في وصيوله للباحثين

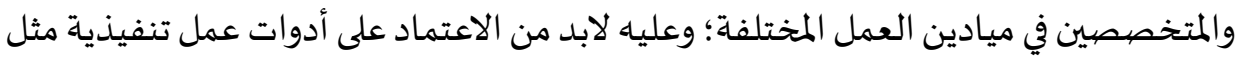

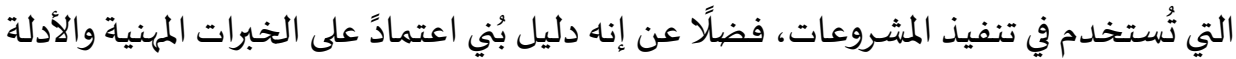

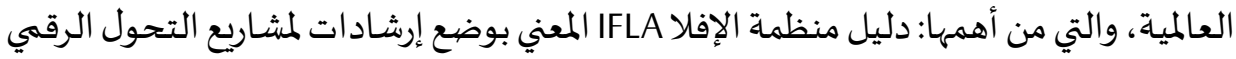
للمجموعات التراثية كالمخطوطات والكتب والصور، وخاصة تلك التي تحتفظ بها لها المكتبات

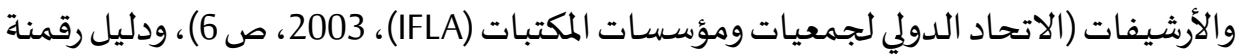


مجموعات مكتبة جامعة ميرلاند Maryland من كتب نادرة ومخطوطات وخرائط وغير ذلك من

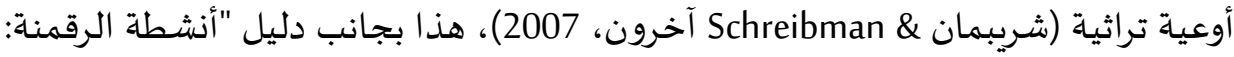
دليل التخطيط للمشروعات وإدارتها" الذي أصدره اتحاد جمعيات الأدلة الإرشادية للرقمنة

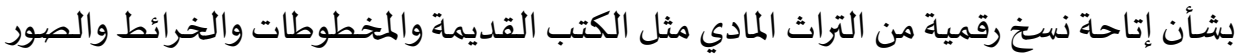

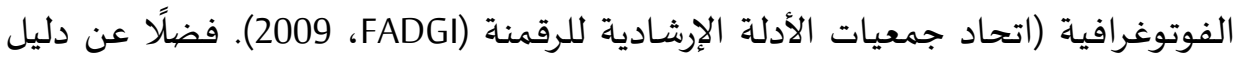
مشروع EUROPEANA REGIA، والذي يحتوي على الخطوات التنفيذية لتوثيق مخطوطات

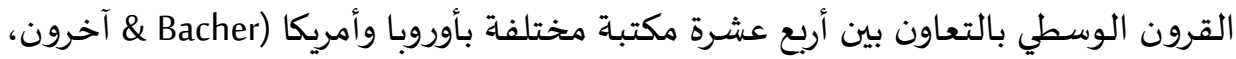

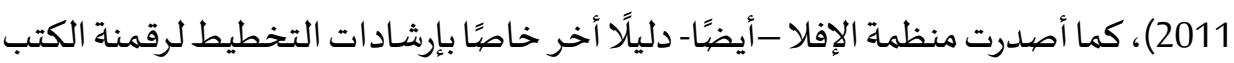

$$
\text { النادرة (الاتحاد الدولي لجمعيات ومؤسسات المكتبات (IFLA)، 2014). }
$$

وقد اتضح للباحث أن النشر الإلكتروني للمخطوطات العبية يمكن أن يتكون من

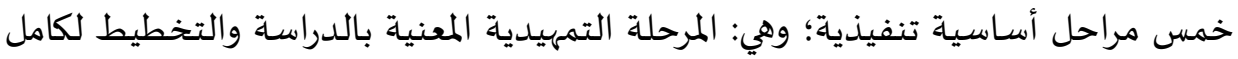
عملية النشر الإلكتروني الخاصة بالمخطوطات العربية، وذلك من حيث تحديد الأهداف

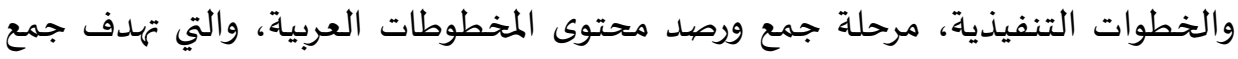
المحتوى النصي المكتوب عن المخطوطات العبية من بيانات فهرسة ووصف كوديكولوجي، وما

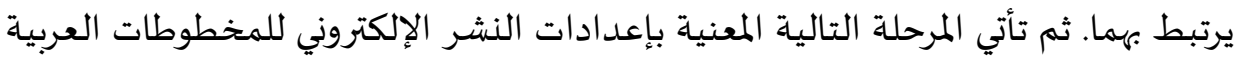
والتي تهدف إلى تجهيز المحتوى الرقمي وإمكانية القيام بعمليات البحث والاسترجاع من من خلاعلال

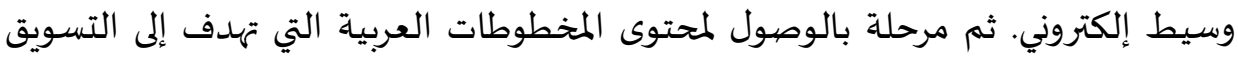

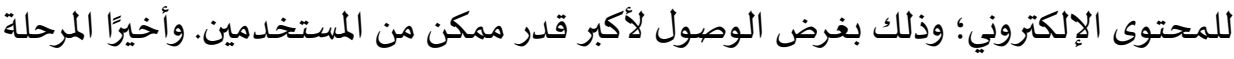

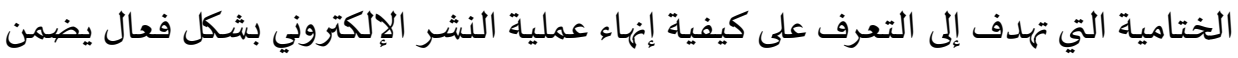

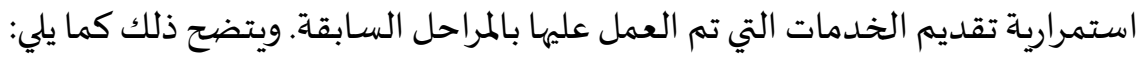
6 المراحل التنفيذية:

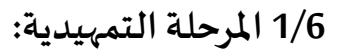

من المقترح أن تمثل هذه المرحلة الخطوات الأولي لعملية النشر الإلكتروني

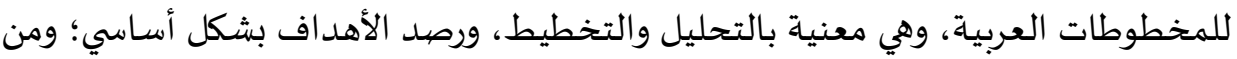
أجل هذه البداية يقترح الباحث استخدام مجموعة من الأدوات التي تعين على هذه الخطوات، ويتبين ذلك كما يلي: 


\section{1. التخطيط لعملية النشر الإلكتروني للمخطوطات العربية:}

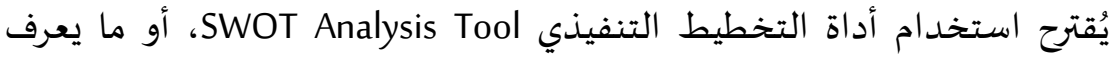

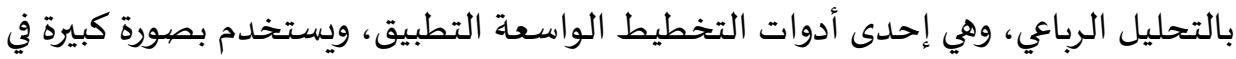
التخطيط من أجل تنفيذ مشروع محدد، وهي تساعد في الوقوف على أربعة اتجاهات متمثلة في نقاط القوة Wtrengths ونقاط الضعف Opeaknesses والفرض Opportunities والتهديدات Threats الإلكتروني للمخطوطات العربية كما يلي: أ. نقاط القوة Strengths: وفيها يتم تحديد نقاط القوة التي تساعد على التنفيذ، وهي تأتي من داخل المكتبة؛ مثل: موافقة إدارة المكتبة ودعمها. تخصيص جزء من ميزانية المكتبة. تواجد المتخصصين من فرق العمل.

ب. نقاط الضعف Weaknesses: وفيها يتم تحديد نقاط الضعف التي تعيق التنفيذ، وهي تأتي من داخل المكتبة؛ مثل:

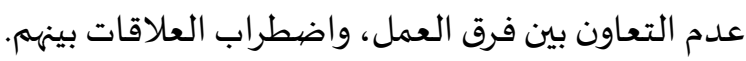
تأخر صرف الرواتب. عدم وجود المعدات الكافية.

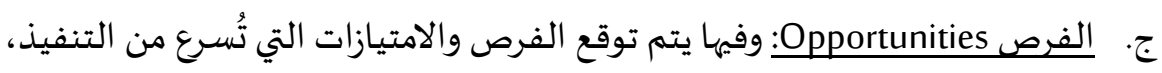
وهي تأتي من خارج المكتبة؛؛ مثل:

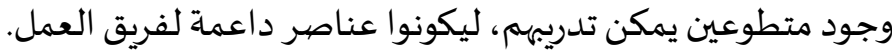

$$
\text { المنح المالية. }
$$

منح التدريب لأفراد فرق العمل لتحسين مهاراتهم. د. التهديدات Threats: وفيها يتم توقع العقبات التي قد تُعطل التنفيذ، وهي تأتي من فئن

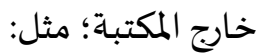

$$
\begin{aligned}
& \text { القرصنة الإلكترونية. } \\
& \text { تأخر دفعات المنح المالية. } \\
& \text { استخراج تصاريح المسح الضوئي. }
\end{aligned}
$$


ومن العرض السابق يتوجب على مسؤولي تنفيذ مراحل عملية النشر الإلكتروني

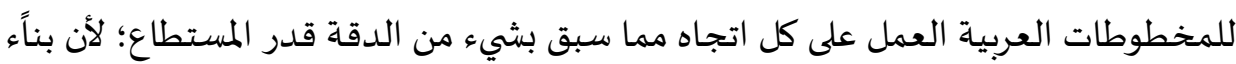
على ذلك سوف يتم تحقيق أقصى استفادة ممكنه من العناصر المتاحة بالمكتبة، وكذلك رسم

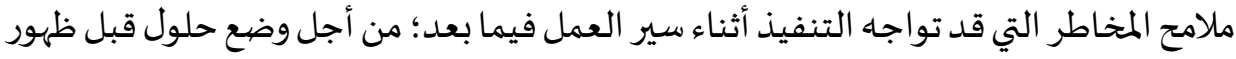

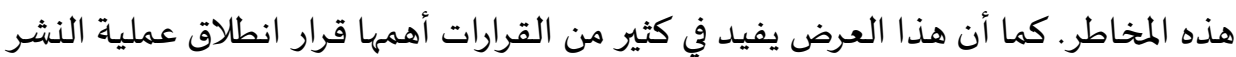
الإلكتروني من عدمها.

2. تحديد الأهداف لعملية النشر الإلكتروني للمخطوطات العنات العربية: يُقترح استخدام أداة تحديد الأهداف المعروفة باسم SMART Goals، وتمتاز هذه الأداة بمجموعة من المعايير التي يجب مراعاتها عند استخد امها من قِبل مسئولي التنفيذ للنشر التهر الإلكتروني للمخطوطات العربية، وتتمثل هذا المعايير في التالي:

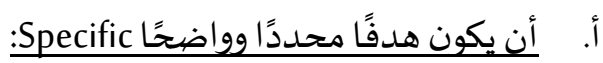

خلال هذا المعيار يتم وصف الهدف، وفي الغالب يكون الهدف العام من عملية النشر الإلكتروني (أو المشروع)، ولتحقيق هذا المعيار لابد من الإجابة عن خمسـة أسئلة كما يلي:

من: من هي الجهات و/أو الأفراد القائمين على التنفيذ؟

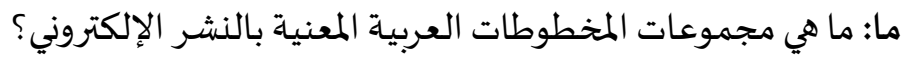

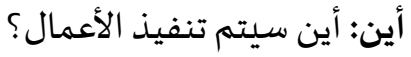
لماذا: لماذا تم اختيار مجموعات المخطوطات العبنيد العمبية؟ (القيمة العلمية / القيمة التاريخية / ضمن سياسة المكتبة لنشر المقتنيات إلكترونيَّا...)

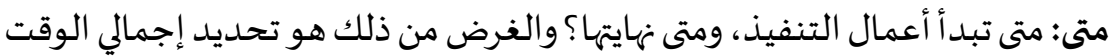
المستغرق للتنفيذ. مثال على ذلك:

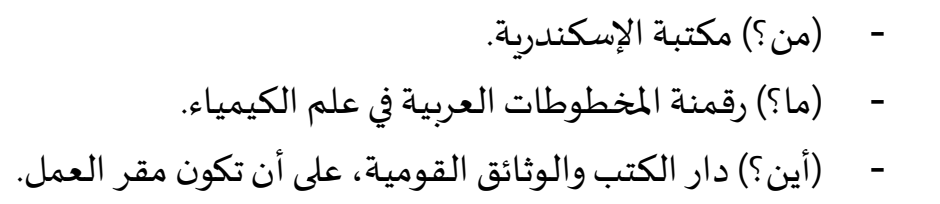


- - لماذا؟) لنشرها إلكترونيًّا من خلال موقع المكتبة؛ وذلك لخدمة الباحثين

المتخصصين.

- (متى؟) وهذا خلال الفترة من يناير إلى أكتوبر 2020.

يُقترح استخدام الصياغة النصية التالية في العقود أو البروتوكولات:

قيام مكتبة الإسكندرية برقمنة المخطوطات العربية في علم الكيمياء المحفوظة بدار

الكتب والوثائق القومية على أن تكون مقر العمل؛ لنشرها إلكترونيَّا من خلال موقع المكتبة؛ وذلك لخدمة الباحثين المتخصصين، وهذا خلال الفترة من يناير إلى أكتوبر 2020. ب. أن يكون هدفًا قابلًا للقياس Measurable:

من خلال هذا المعيار يتم تحويل الأهداف المرجوة إلى أرقام قدر المستطاع؛ وذلك من فن فئس

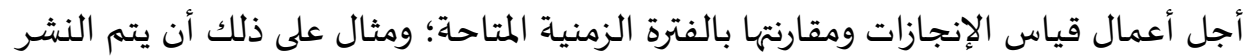

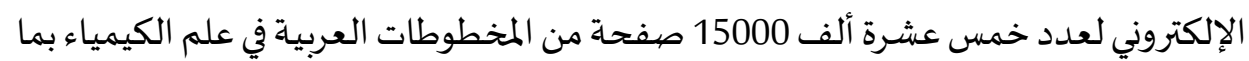

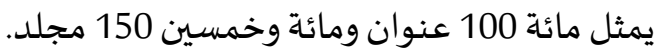

ج. أن يكون هدفًا قابًِا للتحقيق والإنجاز Attainable \& Achievable: خلال هذا المعيار يتم التحقق من وجود العوامل التي تساعد على التنفيذ؛ مثل:

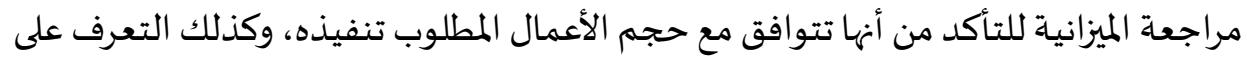

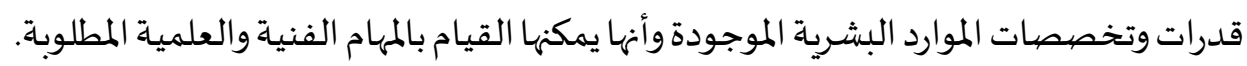

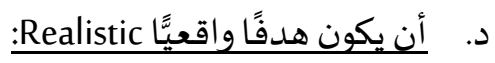

خلال هذا المعيار يتم التأكد من واقعية التنفيذ، ويعتمد ذلك على أن لا يكون هناك تغافل من مسئولي العمل عن بعض المعوقات المعروفة مسبقًا؛ ومثال على ذلك عدم دراسة

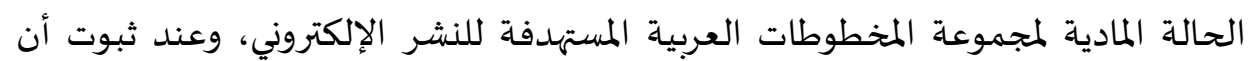

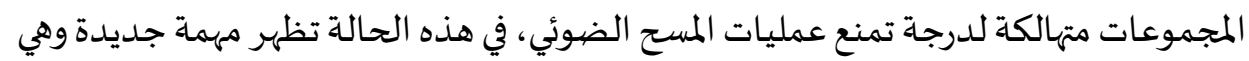
الترميم مما يستغرق وقتًا وتكلفة لم يكونا في خطة العمل من البداية.

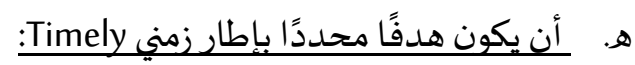
خلال هذا المعيار يتم تقسيم المهام وتحديد الوقت المستغرق لتنفيذ كل مهمة، وكذلك الأنشطة التنفيذية المنبثقة منها. ويمكن أن تكون نقطة البداية لتحقيق ذلك هي إجابة سؤال 
"متى" أحد أسئلة المعيار الأول - سابق الذكر - الخاص بتحديد ووضوح الهدف. وعلى سبيل

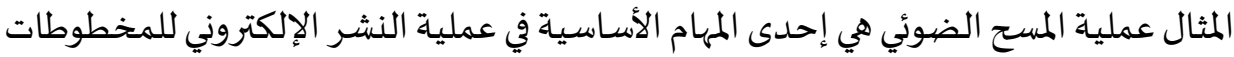

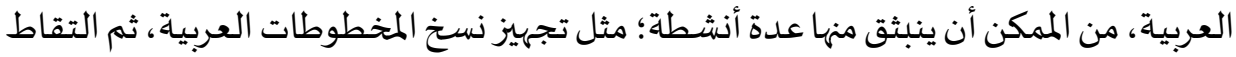
الصور وتسميتها، ثم المعالجة الفنية لصور الصفحات، ثم ربطها بهنها بالبيانات الببليوجرافية بقاعدة البيانات.

ومن خلال تطبيق العناصر السابقة سوف ينتج مجموعة من الخطوات الهامة التي

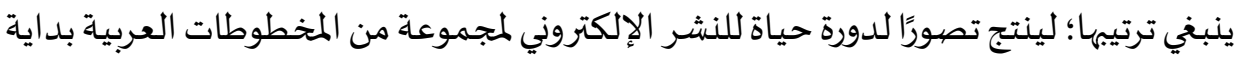

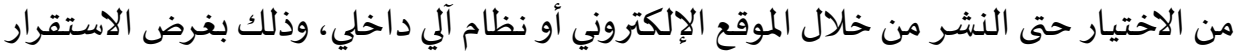

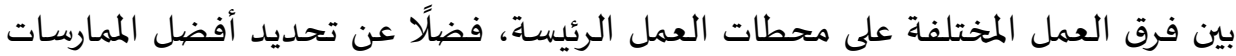
والاحتياجات اللازمة في كل محطة، ويتبين ذلك من خلال الشكل التالي:

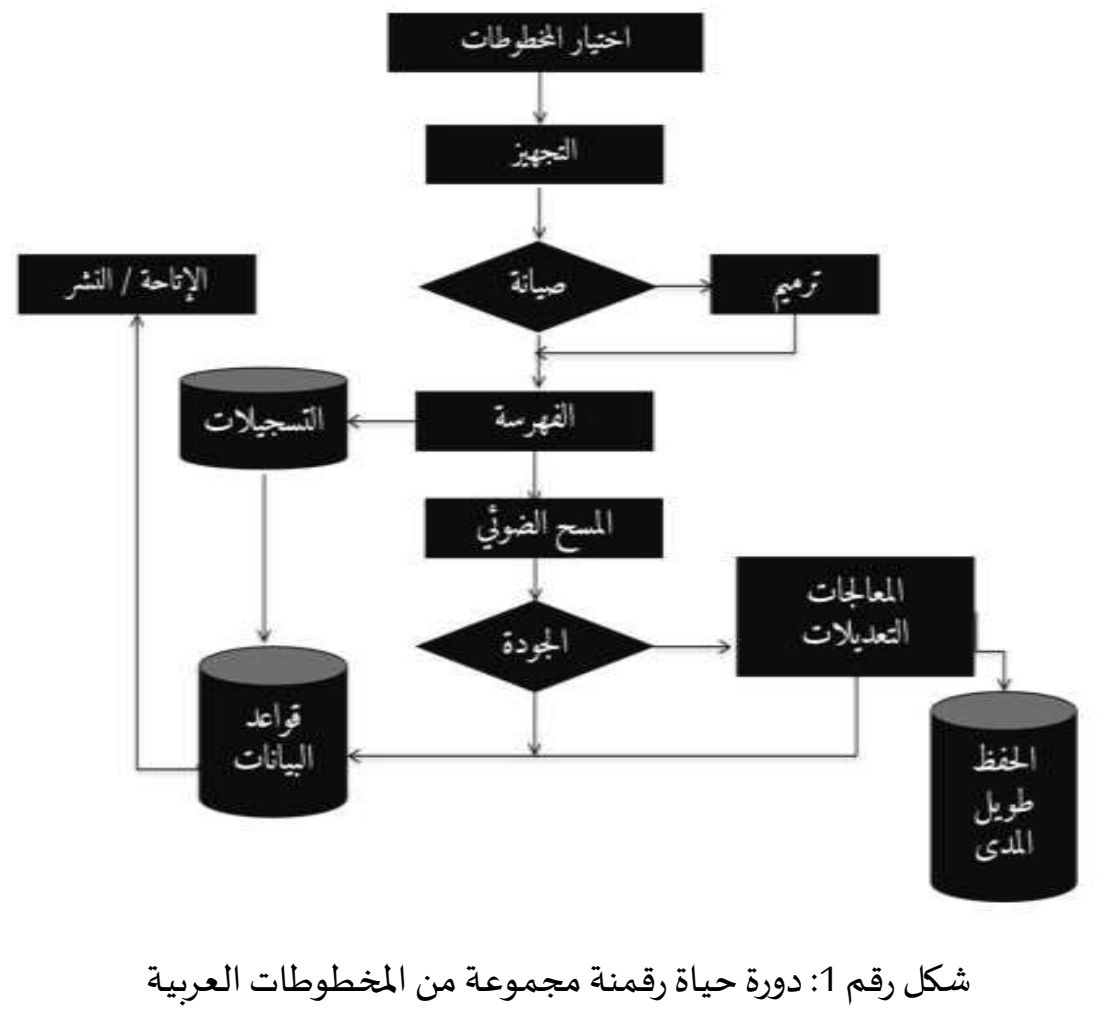




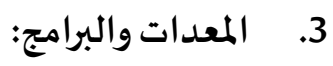

يحاول الباحث عرض المعدات والبرامج الأساسية لعملية رقمنة المخطوطات العربية

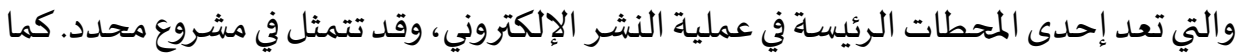
أن هذه المقترحات يمكن الاختيار منها فيما يناسب الحالة المادية للمخطوطات العربية المستهدفة للنشر الإلكتروني، ويتبين ذلك كما يلي: أ. أمعدات:

مجموعة أجهزة الحاسب، ويعود عددها ومواصفاتها إلى حجم المشروع، وكذلك

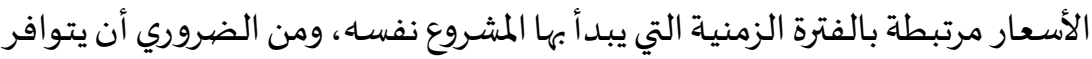

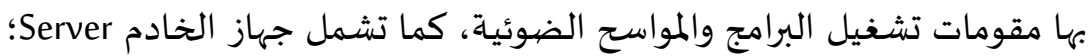
وذلك من أجل بناء شبكة داخلية بمقر عمل المشروع.

Over Head Book ماسحات ضوئية مخصصة للمخطوطات العربية، والتي أهم أشكالها بعريا

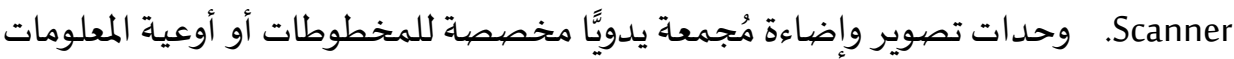

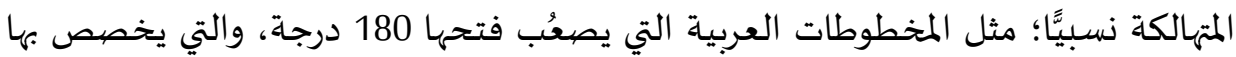

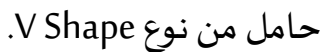

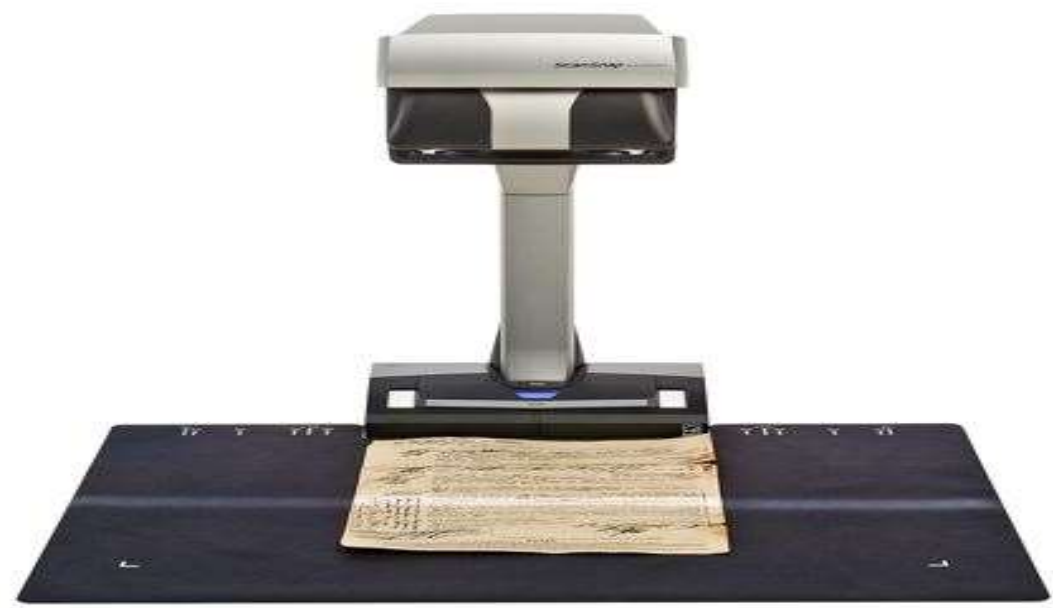

شكل رقم 2: ماسح ضيوئي من فئة 


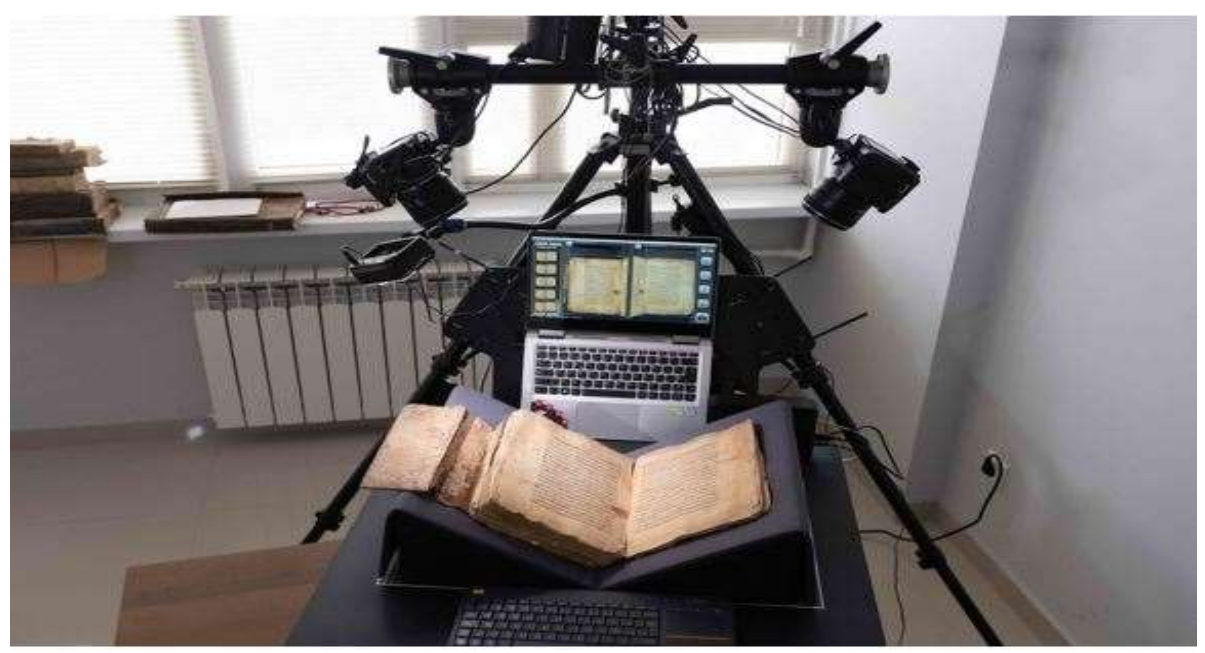

شكل رقم 3: وحدة تصوير مجمعة يدويَّا معها

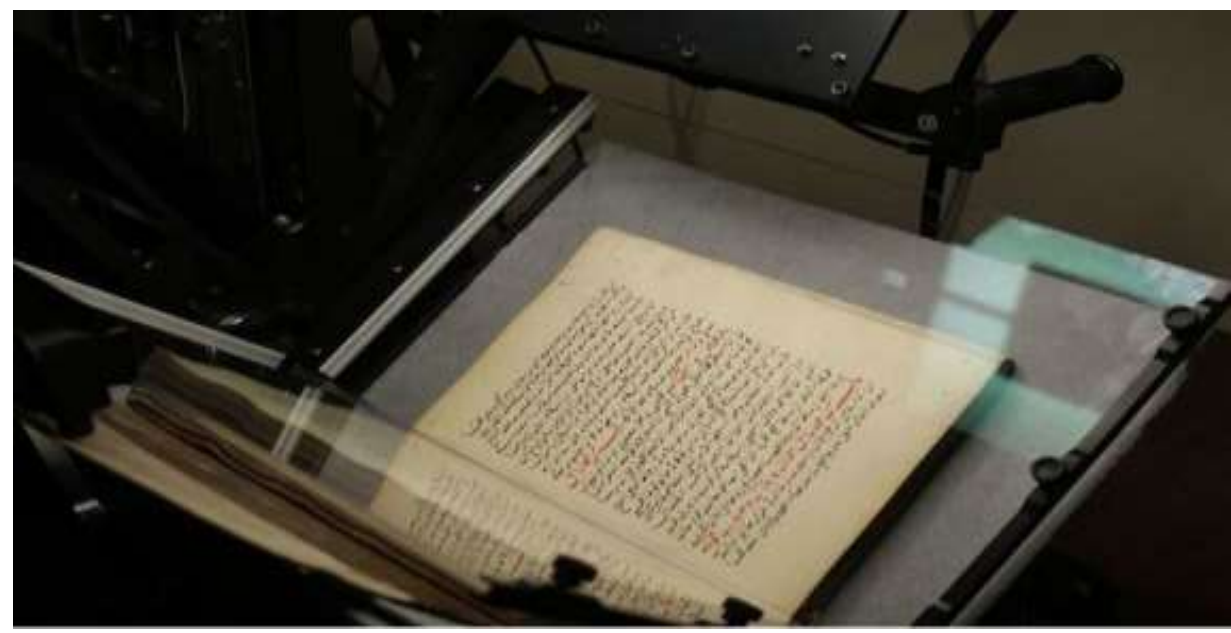

ش Shape* شكل رقم 4: حامل زجاجي من نوع

*https: //www. factumfoundation.org/pag_fa/1339/portablemanuscript-scanner

*https://www.factumfoundation.org/pag_fa/1339/portablemanuscript-scanner 
من الضروري تحديد الهدف من التصوير الرقمي للمخطوطات فإن كان الهدف إعادة

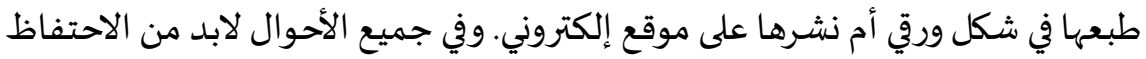

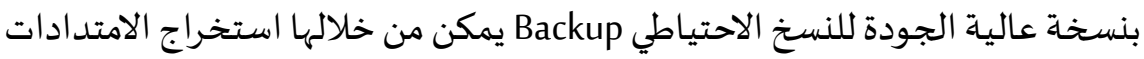

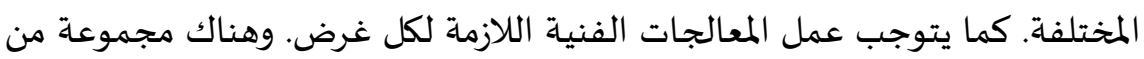
المقترحات التي تساعد في تنفيذ ذلك، ويتبين ذلك كما يلي: Adobe Photoshop الصهور. Light Room كل صور بالبيانات الخاصة بها. Capture One Pro

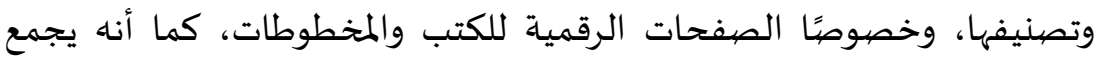
خصائص البرنامجين السابقين وغيرها من البرامج.

\section{2/6 المرحلة الأولى: مرحلة جمع ورصد المحتوى للمخطوطات العربية:}

الهدف الأساسي من هذه المرحلة هي جمع ورصد المحتوى المزمع نشره عن المخطوطات العربية، ولا شك أنه للقيام بذلك لابد من استخدام مجموعة من الأدوات التي أقرها خبراء

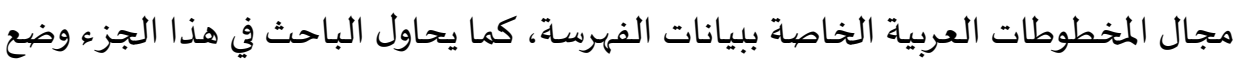

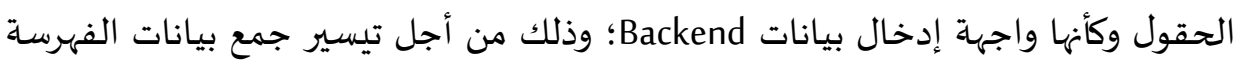

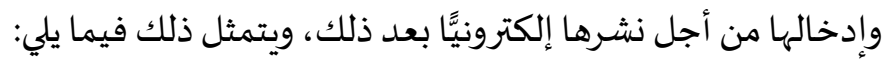


1. الوصف الببليوجرافي:

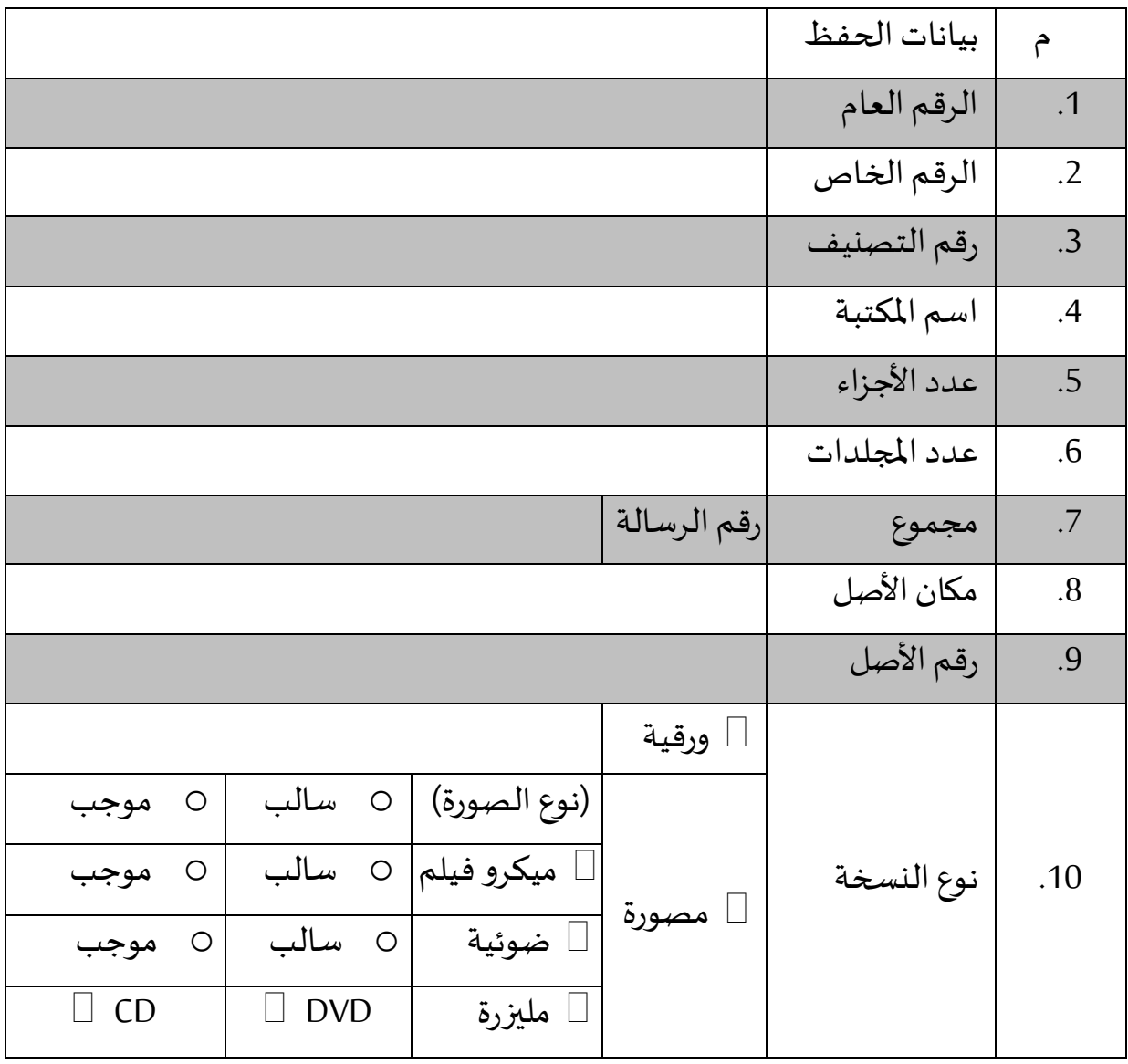

\begin{tabular}{|c|c|c|c|c|c|}
\hline & & & & |بيانات التجليد & م \\
\hline & & 口 حديث & 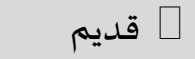 & | التجليد & 1 \\
\hline 口 معدن & ا خشب & 口 جلد & 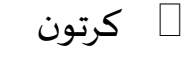 & \multirow{3}{*}{ المادة } & \multirow{3}{*}{2} \\
\hline 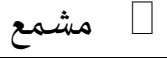 & 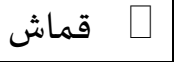 & 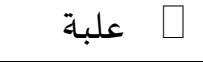 & 口 مشمع & & \\
\hline & & & 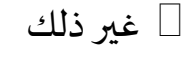 & & \\
\hline 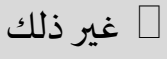 & —— ملونة & — مذهبة & Dضغوطة & زخرفة التجليد & 3 \\
\hline & O ل ا يلزم & O متوسطة & O ماسة & الحاجة إلى التجليد & 4 \\
\hline
\end{tabular}


النشر الإليكترونى للمخطوطات العربية : محاولة لوضع دليل عمل استرشادي

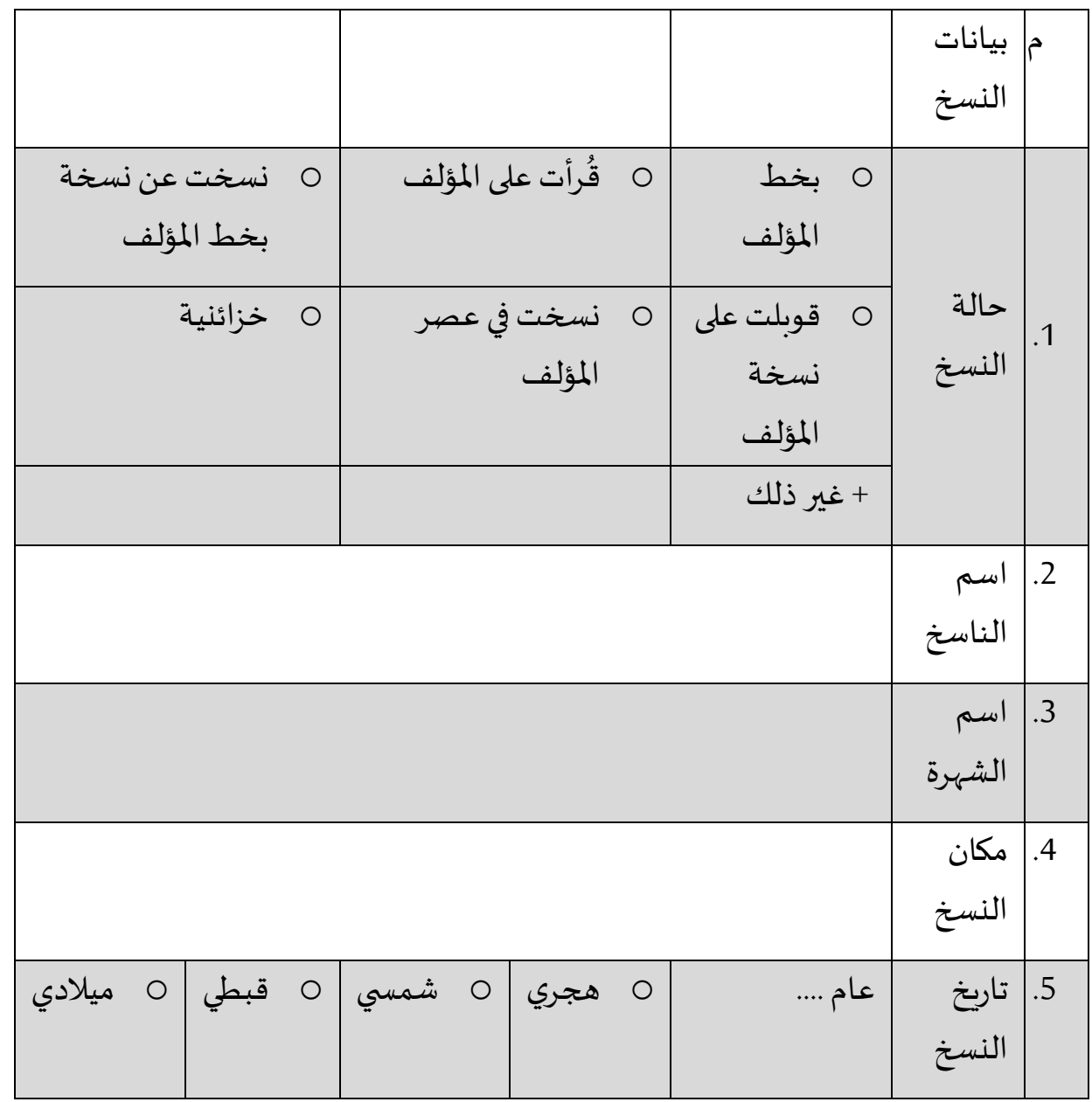




\begin{tabular}{|c|c|c|c|c|c|}
\hline & & & & بيانات المؤلف & 5 \\
\hline & & ע $O$ & O نعم & 0 مجهول المؤلف & .1 \\
\hline & & & & O م في حال لا يتبع & .2 \\
\hline & & & & المؤلف من صفحة & .3 \\
\hline & & & & المؤلف من الغلاف & .4 \\
\hline & & & & المؤلف من المقدمة & .5 \\
\hline & & & & المؤلف من الخاتمة & .6 \\
\hline & & & & المؤلف الموثق & .7 \\
\hline & & & & كنية المؤلف & .8 \\
\hline & & & & لقب المؤلف & .9 \\
\hline & & & & نسب المؤلف & .10 \\
\hline & كام .... هـ & أو في حلد & عام ....... هجريا & & 11 \\
\hline & رن .... هج & أو من أه & بعد عام ...... هجريا & & \\
\hline طبعة & صفحة & جزء اء & الأعلام للزركلي & & \\
\hline طبعة & صفحة & 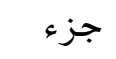 & معجم المؤلفين لكحالة & & \\
\hline طبعة & صفحة & جزء اء & للبغدية العارفين & مراجع تحقيق المؤلف & .12 \\
\hline طبعة & صفحة & جزء اء & + غير ذلك & & \\
\hline & & شكل & & مؤلف ذات علاقة & .13 \\
\hline & & شكل & & + مؤلف أخر ذات علاقة & .14 \\
\hline
\end{tabular}


النشر الإليكترونى للمخطوطات العربية : محاولة لوضع دليل عمل استرشادي

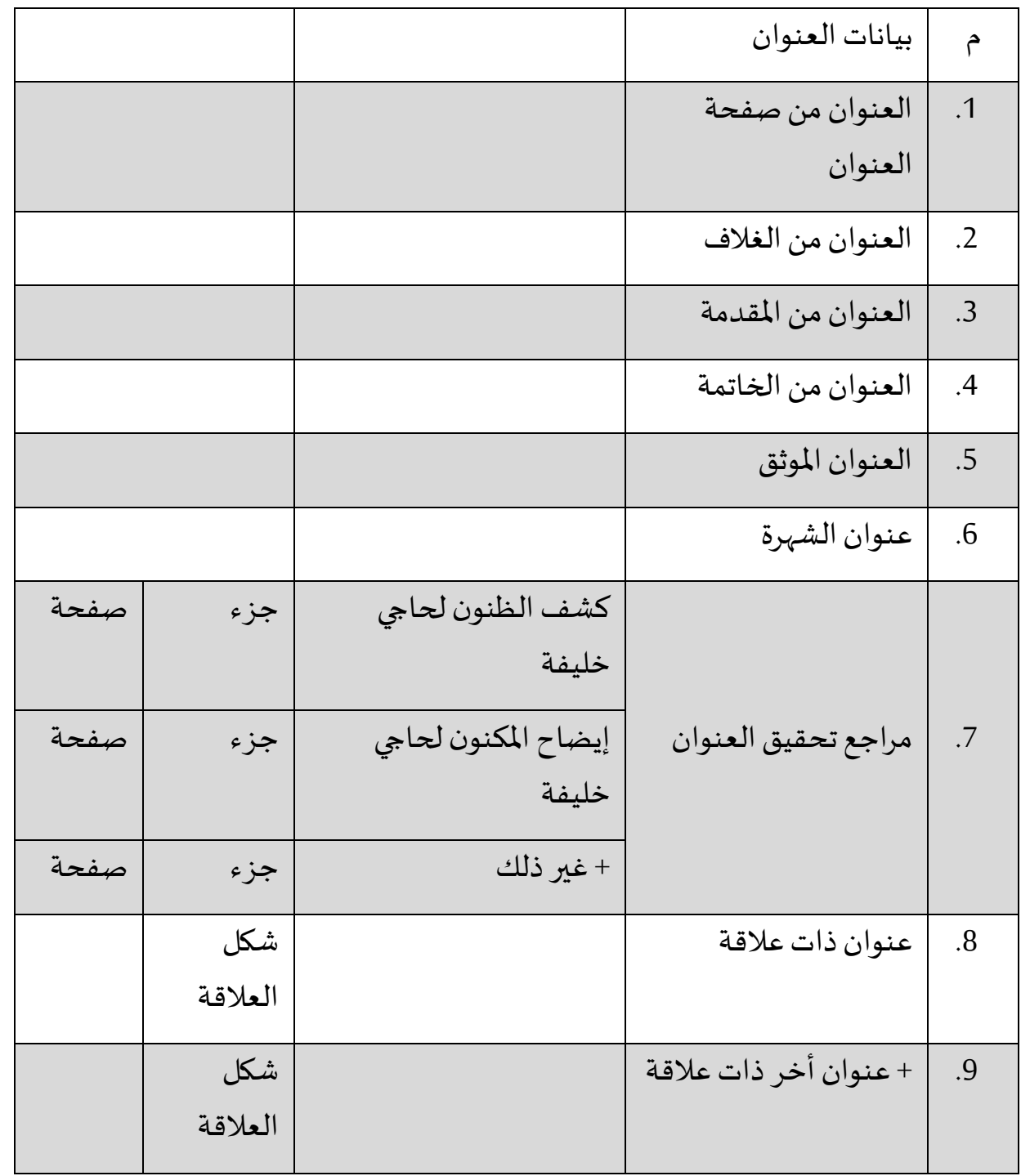




\begin{tabular}{|c|c|c|c|c|c|}
\hline & & & & الوصف المادي & \\
\hline & & العرض & الطول & المقاس & .1 \\
\hline & & & & عدد الأوراق & .2 \\
\hline & & & & المسطرة & .3 \\
\hline O & O لوحة & O لفافة & O & الشكل & .4 \\
\hline 0 & O بردي & 0 & O ورق & \multirow{2}{*}{ المادة } & \multirow{2}{*}{.5} \\
\hline O غير ذلك & O & O خشب & 0 & & \\
\hline ( طيارات & 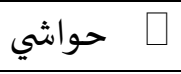 & 口 علامات مائية & D إطارات & \multirow{3}{*}{ النسخة تحتوى على } & \multirow{3}{*}{.6} \\
\hline & 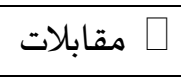 & | & | & & \\
\hline 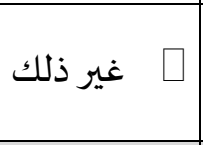 & ـارتخ أقدم & 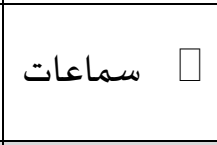 & 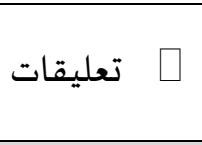 & & \\
\hline \multirow[t]{2}{*}{ O رواية } & O سند & O & م إجازة & \multirow[b]{2}{*}{ ال الإجازات } & \multirow[b]{2}{*}{.7} \\
\hline & & أقدام & 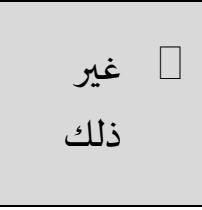 & & \\
\hline \multirow[t]{5}{*}{ | ل هندسية } & 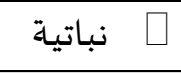 & 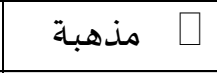 & 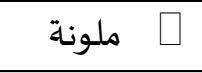 & الزخارف والحليات & .8 \\
\hline & & ملون & 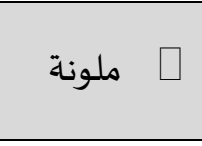 & الصور التوضيحية & .9 \\
\hline & مقاب & الآخر & الأول & النسخة ناقصية & 10 \\
\hline & & & & 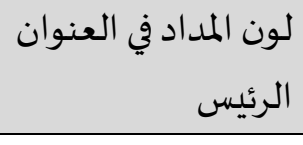 & .11 \\
\hline & & & & 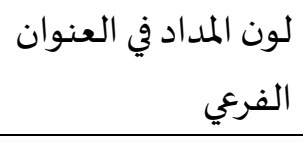 & .12 \\
\hline
\end{tabular}


النشر الإليكترونى للمخطوطات العببية : محاولة لوضع دليل عمل استرشادي

\begin{tabular}{|c|c|c|c|c|c|}
\hline & & & & الوصف المادي & \\
\hline & & & & لون المداد في النص & .13 \\
\hline & + غير ذلك & Dذ مذبة & ( & الفواصل & .14 \\
\hline O تعليق & 0 & O رقعة & O معتاد & \multirow{3}{*}{ نوع الخط } & \multirow{3}{*}{.15} \\
\hline O كوفي & O ديواني & م فارسي & O مغربي & & \\
\hline & ذ ذ غلك & 0 مضبوط & O مثلث & & \\
\hline \multirow[t]{2}{*}{ أطراف } & $\square$ & ～ا تلوث & D أكل أرضية & \multirow[t]{2}{*}{ حالة النسخة } & \multirow[t]{2}{*}{.16} \\
\hline & ملاحظة & + غير ذلك & 口 & & \\
\hline
\end{tabular}

\begin{tabular}{|l|r|l|}
\hline & م & \\
\hline & 1 الفاتحة والخاتمة & \\
\hline & الفاتحة & الخاتمة \\
\hline
\end{tabular}

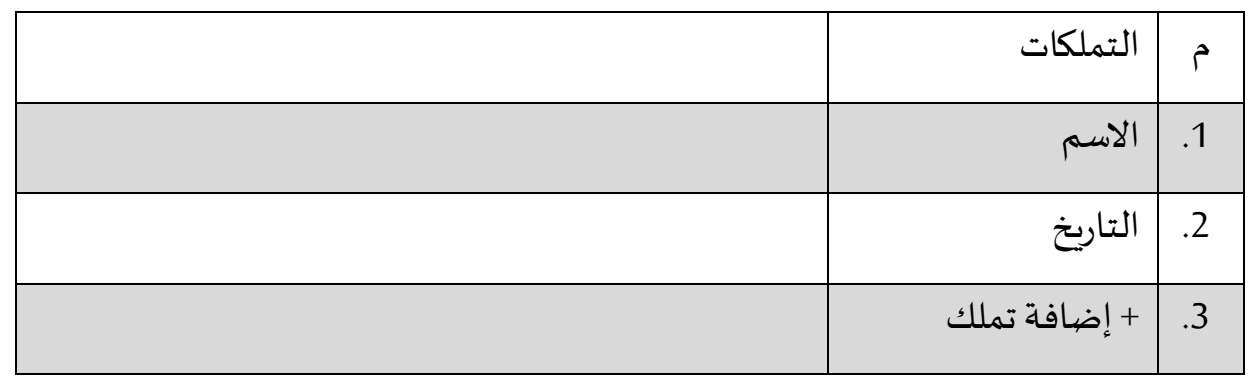




\begin{tabular}{|c|c|c|}
\hline & التوقيفات & م \\
\hline & من & r \\
\hline & على & .1 \\
\hline & التاريخ & .2 \\
\hline & + إضـافة توقيف & .3 \\
\hline
\end{tabular}

\begin{tabular}{|c|c|c|}
\hline & رؤوس الموضيوعات & م \\
\hline & رأس موضوع 1 & .1 \\
\hline & رأس موضيوع 2 & .2 \\
\hline & رأس موضوع 3 & .3 \\
\hline & + + موضيوع & .4 \\
\hline
\end{tabular}

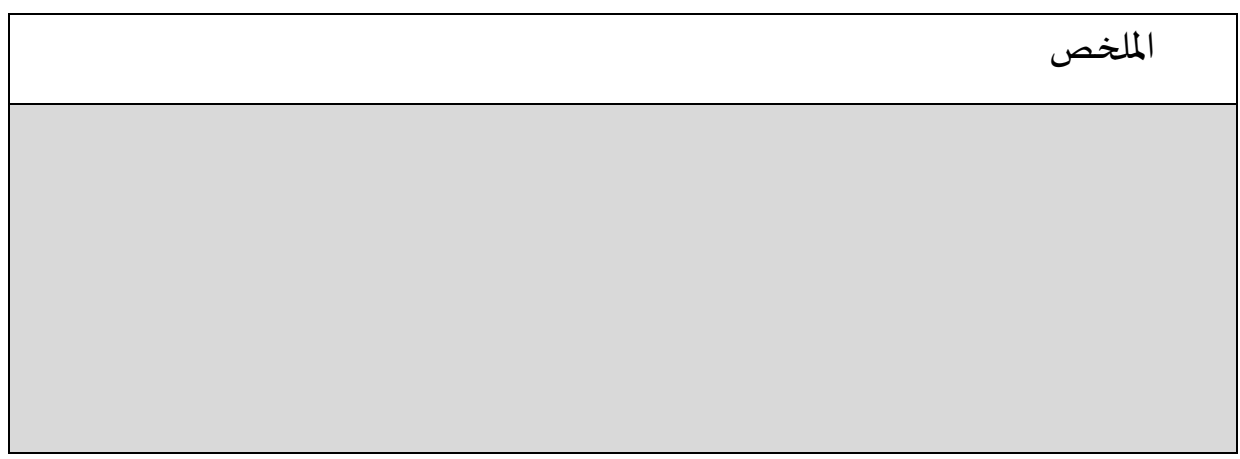


النشر الإليكترونى للمخطوطات العببية : محاولة لوضع دليل عمل استرشادي

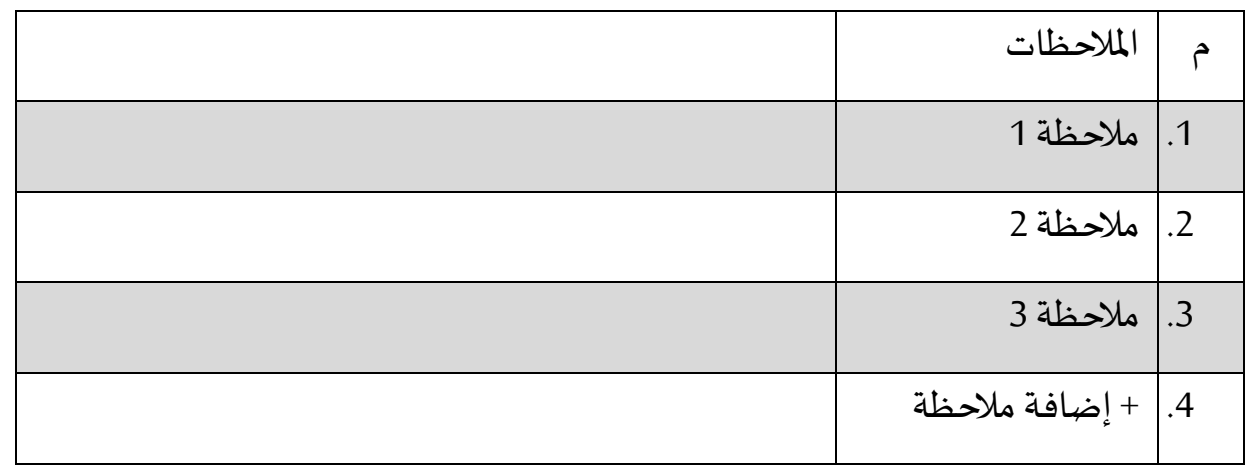

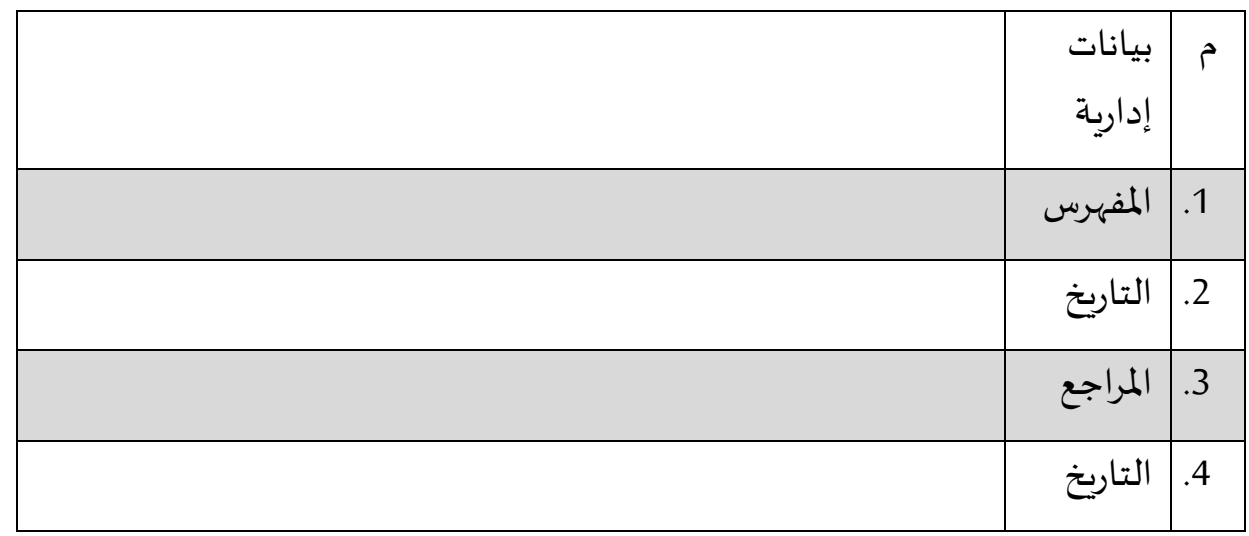

2. الوصف الكوديكولوجي:

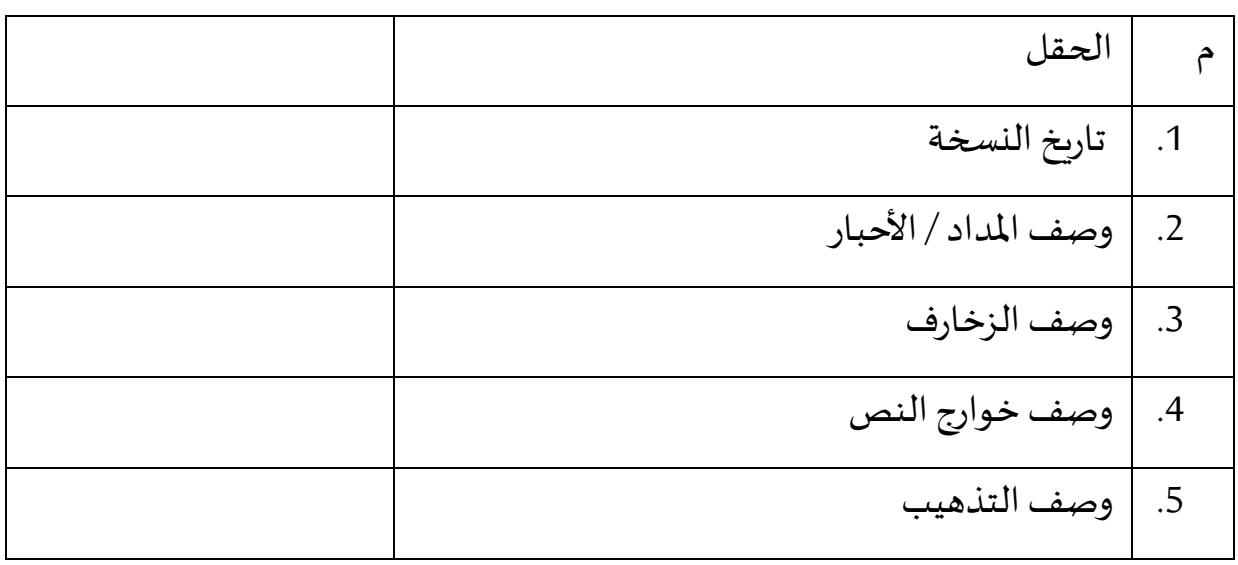




\begin{tabular}{|c|c|c|}
\hline & 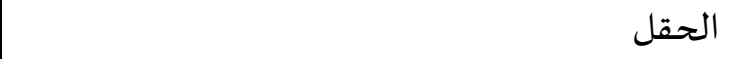 & م \\
\hline & وصفف حالة التجليد & .6 \\
\hline & وصف مساحات حدود الصفحة & .7 \\
\hline & وصف محتوى صفحة العنوان & .8 \\
\hline & وصف مواد التجليد و/أو البطانة & .9 \\
\hline & وصف أنماط التجليد وزخرفتها & 10 \\
\hline & وصف العلامات مائية & .11 \\
\hline & اسمَ مُزين المخطوط & 12 \\
\hline & بيان وجود أكثر من ناسخ & 13 \\
\hline & وصفف أنواع الكراسـات & 14 \\
\hline & عدد الأوراق بالكراسـة الواحدة & 15 \\
\hline & وصف نظام التعقيب بصفحات الكراس & 16 \\
\hline & وصف لوجود شـوائب & 17 \\
\hline & وصيف عن وجود تمزيق & 18 \\
\hline & وصف حرد المتن & 19 \\
\hline & وصف الإجازات & 20 \\
\hline & وصف الأختام & 21 \\
\hline & ملاحظات & 22 \\
\hline
\end{tabular}




\section{3/6 المرحلة الثانية: إعدادات النشر الإلكتروني للمخطوطات العربية:}

تختص هذه المرحلة بمراعاة العناصر المقترحة في تنفيذ تجارب النشر الإلكتروني من خلال شبكة الإنترنت، وليست من أجل عرض العناصر المطلوبة توافرها في بناء مواقع المكتبات

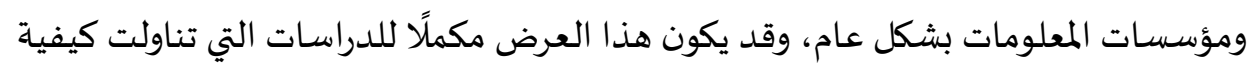

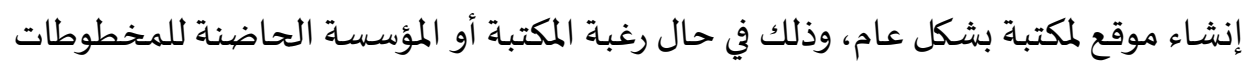

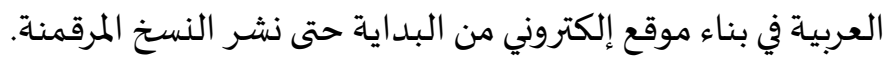

\section{1. التصفح Browsing:}

أ. دعم التصفح من خلال القوائم الثابتة، وقد تتمثل هذه القوائم في:

$$
\begin{aligned}
& \text { قائمة التصنيفات الموضوعية. } \\
& \text { قائمة العصور الزمنية. } \\
& \text { قائمة أبجدية لعرض فئات أسماء المؤلفين. } \\
& \text { ب. دعم التصفح من خلال ترتيب نتائج البحث: }
\end{aligned}
$$

إمكانية الترتيب الهجائي لأسماء المؤلفين، ويتم اختيار الترتيب باسم الشهرة أو أولئ

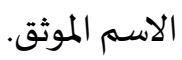

ترتيب زمني بأحد التواريخ المرتبطة بالمخطوط؛ كتاريخ النسخ أو تاريخ ميلاد

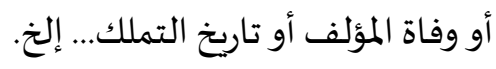

ج. دعم التصفح من خلال المجموعات المميزة: الأكثر مشاهدة.

$$
\text { الأكثر تحميل. (الاكتر مثاهدة. }
$$

د. دعم التصفح من خلال قوائم التصفية باستخدام العناصر الأساسية؛ كالمؤلف تحميل

$$
\text { والتواريخ والموضوع والموقع الجغرافي. }
$$

هـ دعم التصفح من خلال النتائج المرتبطة:

دعم التصفح من خلال نتائج البحث مشابهاة.

ظهور نتائج ذات علاقة من مؤلفين و/أو عناوين بالمخطوطة الماتها التي اختارها 
2.

أ. دعم البحث في بيانات فهرسة المخطوطات العربية.

ب. دعم البحث في جزء من نص المخطوطات العربية (إن توافر).

ج. دعم البحث في النص الكامل المخطوطات العربية (إن توافر).

3.

أ. دعم عرض صفحة واحدة من المخطوط منفردة Page on Full Screen. ب. دعم التمرير عبر الصيور المصغرة Thumbnail لمشاهدة محتوى المخطوطة

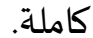

Full جعم عرض الصفحات الكاملة بحجم شاشة العرض للمخطوط،

.Screen

4. الملاحة في الصفحات المرقمنة Navigation: أ. دعم استخدام أسهم لوحة المفاتيح للانتقال إلى صفحات المخطوطات لماتهات

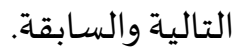
ب. دعم الانتقال المباشر إلى رقم صفحة المخطوط المطلوبة إما بإدخال رقم الصفحة يدويَّا، أو عن طريق تحديده من قائمة.

5. استخدام الصفحات المرقمنة:

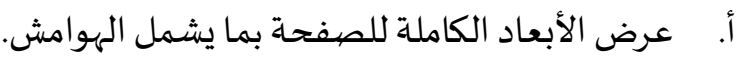

ب. دعم استخدام العدسة المكبرة Zoom in.

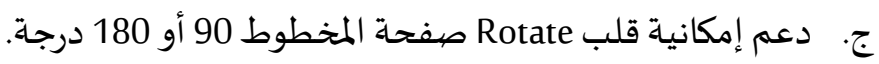

6.

أ. دعم تحميل صفحة أو صفحات محددة من المخطوط.

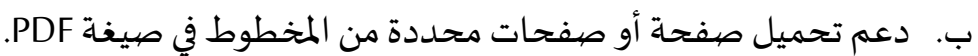
ج. دعم تحميل النص الكامل للمخطوط.

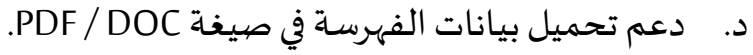

هـ دعم اختيار أنوع صيغ الملفات قبل التحميل (TIFF / JEPG / PDF).

و. دعم اختيار جودة الملفات قبل التحميل. 


\section{7. الاستشهاد المرجعي Citation:}

أ. استخدام بيانات المخطوطات المرجي المات العربية للاستشهاد المرجعي.

ب. طلب حقوق النسخ لاستخدام بيانات المخطوطات العربية للاستشهاد

المرجعي.

:

أ. دعم عرض روابط خارجية ذات صلاة بالمخطوط.

ب. دعم عرض روابط لعناصر مرتبطة بنتيجة البحث داخل الموقع.

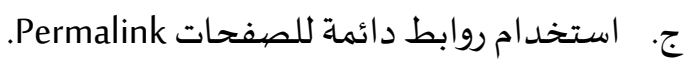

د. مراعاة تسمية الروابط بشكل يلائم المحتوى الذي تحليل المستخدم إليه.

\section{9. التحكم بالصفحات المرقمنة:}

أ. دعم استخدام القوائم المفضلة Favorite List.

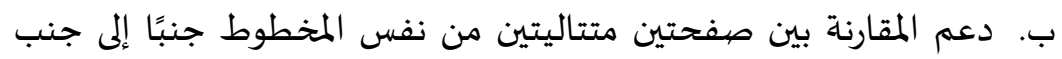

.Book View

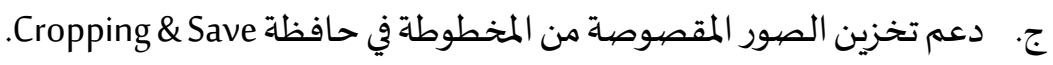

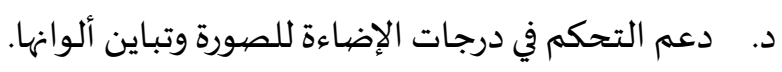

10. دعم المحتوى Sontent Support

أ. السماح للمستخدمين بإضافة نصوص أو أو صور رقمية.

ب. السماح للمستخدمين بتقييم الخدمات (من خلال استبيان على سبيل

المثال).

ج. السماح للمستخدمين بإضافة تعليقات.

د. السماح لمدير النظام بمراجعة مشاركات المستخدمين قبل نشرها.

:Sharing 11. المشاركة دم:

أ. السماح للمستخدمين بمشاركة المحتوى عبر مواقع التواصل الاجتماعي. ب. السماح للمستخدمين بمشاركة المحتوى عبر البريد الإلكتروني. 
4/6 المرحلة الثالثة: الوصول لمحتوى المخطوطات العربية:

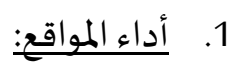

أ. دعم سرعة التصفح بالموقع.

ب. دعم سرعة تصفح المخطوطات العربية.

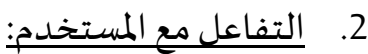

أ. دعم وجود مؤشر لعدد الزوار بالموقع.

ب. توجياه سؤال للمستخدم عن كيفية وصوله بالموقع.

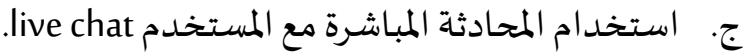

3. إجراءات تحسين وصول محرك البحث للموقع مع :Search Engine Optimization

أ. بناء الروابط الصفحات URL Structure بشكل منطقي.

ب. استخدام بروتوكول HTTPS حتي يكون الموقع أكثر أمانًا لدى محركات البحث مثل مُك

جوجل.

Unique, Accurate Page ج. الدقة في بناء عناوين الصفحات وأن تكون غير مكررة

.Titles

د. توافر وصف ملائم لمحتوى الموقع في القسم الخاص بواصفات البيانات

Metadata

هـ دعم ظهور الموقع في النتائج الأولى لدى محركات البحث، والتي من أهمها جوجل. 4. الأفكار التسويقية عبر مواقع التواصل الاجتماعي

بحكم أن موقع فيسبوك Facebook هو الموقع الأول بين مواقع الشبكات الاجتماعية،

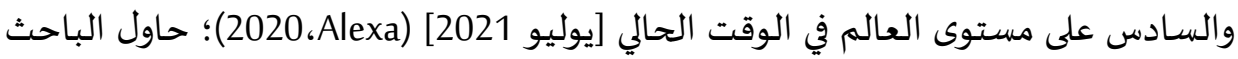

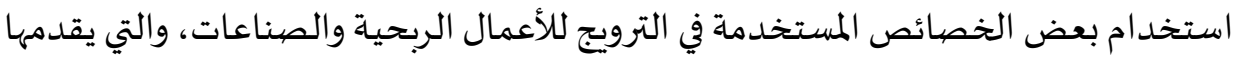
موقع فيسبوك بشكل احترافي بغرض الوصول إلى العملاء المهتمين بمنتج محدد (Miller، ص 7)، ويسعى الباحث مستغلاً هذه الخصائص في دقة الوصول إلى المستفيدين المهتمين

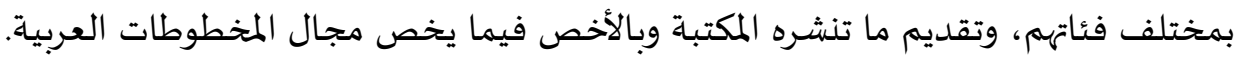

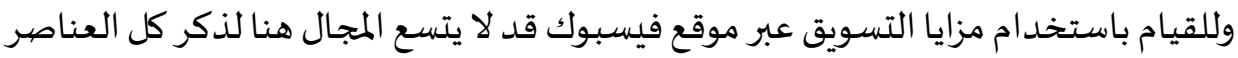


الخاصة بهذا الأمر بشكل كامل، وإنما يحاول الباحث عرض العناصر الأساسية التي من خلالها

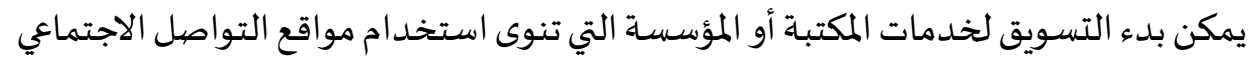
للإعلان خدماتها؛ ويتبين ذلك كما يلي:

$$
\text { أ. تحديد الأهداف من التسويق عن طريق موقع فيسبوك: }
$$

لابد من إدارة المكتبة وضع الخطة التسويقية والتي فيها يتم تحديد الأهداف من عملية

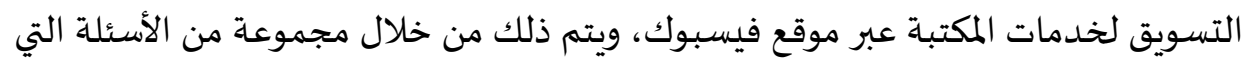

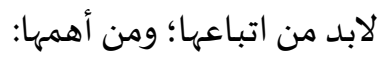

هل تريد المكتبة زيادة المستفيدين بشكل عام؟

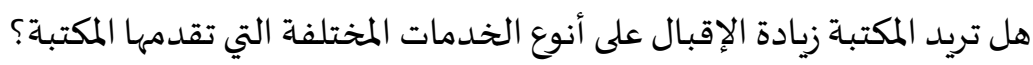

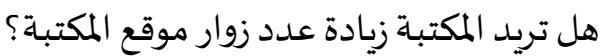

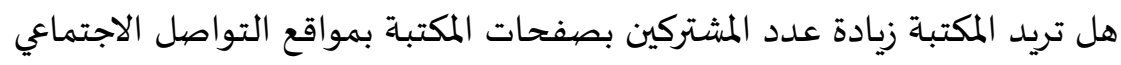

المختلفة؟ تربد

ب. إنشاء صفحة موقع فيسبوك احترافية للمكتبة:

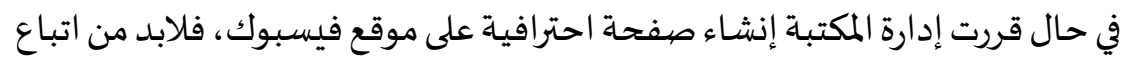

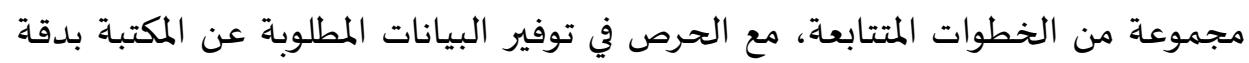

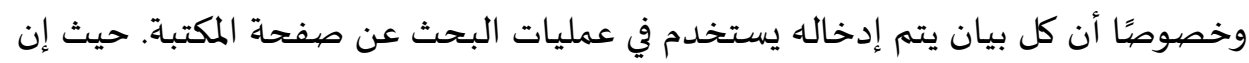

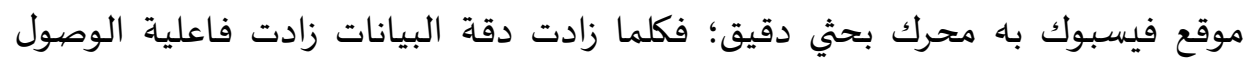

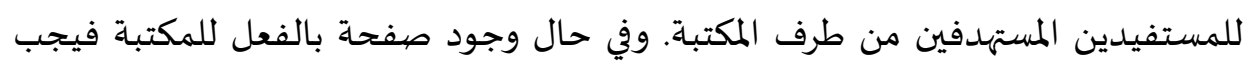
مراجعة البيانات الخاصة بها، ولإنشاء صهفحة جديدة يمكن اتباع الخطوفات المكتية وفي التالية: اختيار نوع الصفحة: يتوافر نوعان من الصفحات، وما يناسب المكتبة هو اختيار Community or Public Figure إضافة الشعار الخاص بالمكتبة و/أو صورة عامة للمكتبة من خلال Add a Profile

.Picture

عمل اسم مستخدم باسم المكتبة من خلال Create Facebook Username. 
تعديل صفحة البيانات من خلال Edit Page Info. استكمال البيانات: بهذه الصفحة يظهر مجموعة من الحقول الرئيسـة والفرعية التي ملي ماتيات

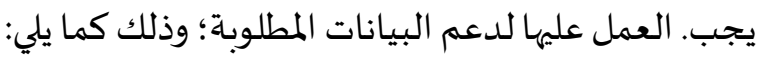
:General

من خلاله يتم إدخال نص تعريفي يشمل رؤية وأهداف Description

$$
\text { المكتبة. }
$$

Category - من خلاله يتم إدخال الخدمات التي تقديمها المكتبة. Contact

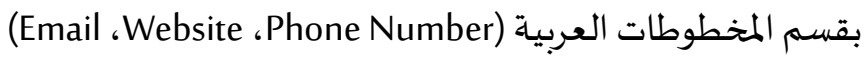
:Location - من خلاله يُحدد الموقع الجغرافي الخاص بالمكتبة على :

$$
\text { الخريطة. }
$$

Service Area -

$$
\text { تحديد المناطق الجغرافية التي يمكن تقديم الخدمة لها. }
$$

Hours

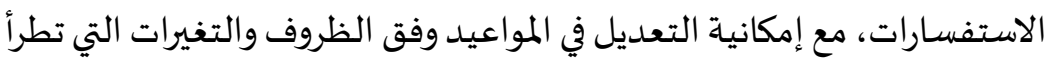
على أنظمة العمل بالمكتبة.

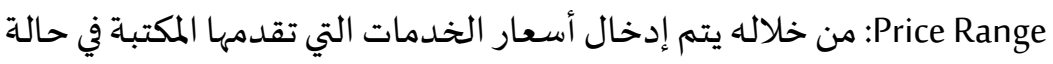
إن كانت الخدمات مدفوعة؛ مثل خدمات تصوير صفححات المخطوطات العبات العبية. :Privacy Policy موقع المكتبة إن وجد، أو كتابة نص سياساة الخصوصة.

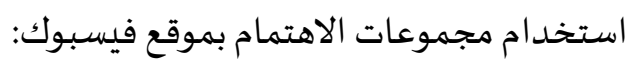

قامت إدارة موقع فيسبوك في السنوات الأخيرة بتقليل حجم Organic Reach وهو

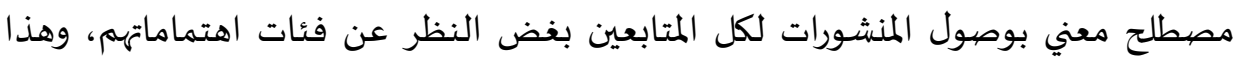

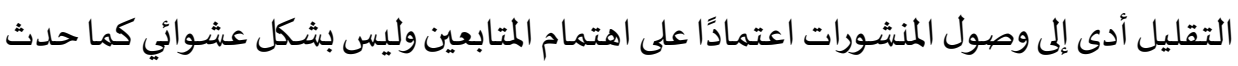

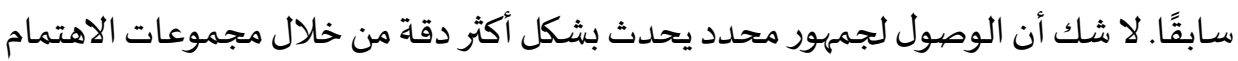


أو ما يعرف بال Facebook Groups. ومن الأمور الهامة التي يجب مراعاتها عند إنشاء واستخدام

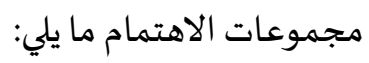

يمكن إنشاء مجموعة اهتمام بنفس اسم صفحة المكتبة على فيسبوك حتى يتم

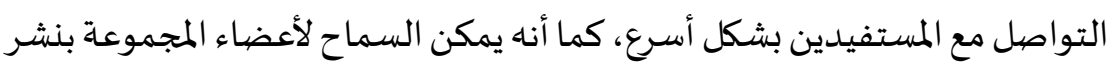

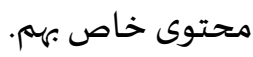

عدم السماح للمستفيدين بنشر التعليقات على صفحة المكتبة؛؛ وذلك حتى لا تتحول

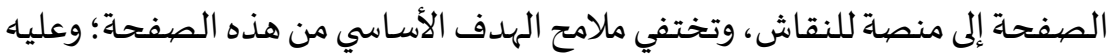

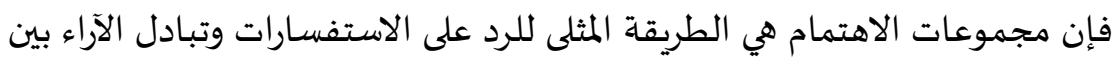
المستفيدين.

لابد من البحث عن مجموعات الاهتمام الأخرى التي لها حرص في قضايا المخطوطات

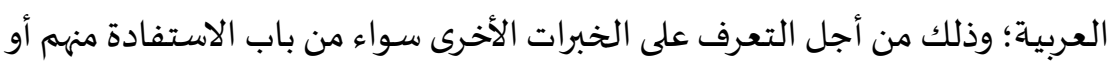
من أجل تزويدهم بما يحتاجون.

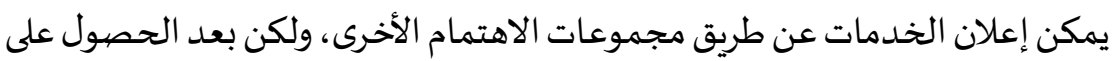

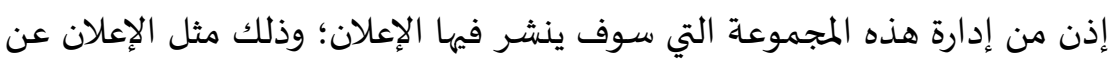

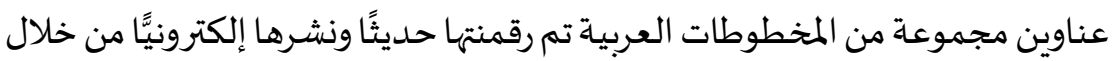

$$
\text { د. موقع استخدام الإعلانات المدفوعةة: }
$$

الإعلانات المدفوعة من شأنها تعزيز وصول صفحة المكتبة إلى المستفيدين المحددين

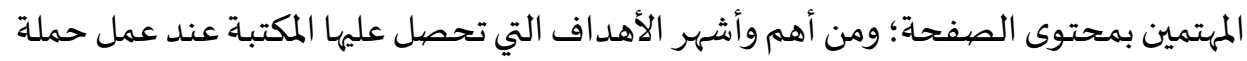
إعلانياة مدفوعة على موقع فيسبوك:

الحصول على المزيد من المتابعين لصفحة المكتبة على موقع فيسبوك. الحصول على زوار لموقع أو لمدونة المكتبة على شبكابكة الإنترنت.

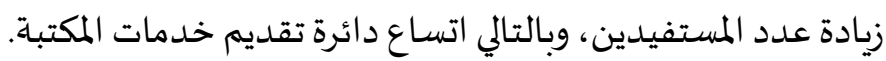
الحصول على المزيد من المشاهدات ملفات الفيديو التي تصديدرها المكتبة. زيادة مرات تحميل التطبيق الخاص بالمكتبة. 


$$
\text { هـ التعرف على جمهور المستفيدين: المزيد من الفاعلية لمنشورات المكتبة. }
$$

يمكن التعرف على اهتمامات المستفيدين عن طريق التحليلات والبيانات التي يتم الحصول عليها عن طريق خاصية Page Analytics المعنية يمكن معرفة كثير من الأمور عن اهتمامات المستفيدين؛ وعليه يمكن معرفة نوعية المحتوى الذي يفضله المستفيدون، وأيضًا الأوقات التي يتواجدون بها، ومتوسط أعمارهم، ومختلف المعلومات التي تساعد في زيادة فاعلية الوصول للمستفيدين.

\section{و. التواصل مع المستفيدين:}

لابد من التواصل مع المستفيدين المشتركين والمتواجدين على صفحة المكتبة بشكل

$$
\text { فعال؛ ومن أهم الخطوات في هذا السبيل: }
$$

توجياه السؤال للمستفيدين بشكل مباشر عن احتياجاتهم (مثل هل تحتاج لعنوان

$$
\text { محدد من المخطوطات العربية في شكل رقمي؟). }
$$

القيام باستطلاعات الرأي عن مستوى الخدمة المقدمة، وما هي سُبل تحسين تلك

$$
\text { الخدمات. }
$$

استخدم البث المباشر Facebook Live للإجـابة عن أسئلة المستفيدين والتواصل

$$
\text { بشكل مباشر معهم. }
$$

التواصل عن طريق خدمة Facebook Messenger، ويمكن استغلال هذه الخاصية في تفعيل خدمة الرد على الاستفسـارات بشكل فوري، مما يزيد من ثقة المستفيد بالمكتبـة وفريق عملها، وبالطبع كل ذلك يتطلب جاهزية في الرد على الاستفسـارات بدقة

$$
\begin{aligned}
& \text { وكفاءة. } \\
& \text { ز. تحليل نتائج التسـويق: }
\end{aligned}
$$

لابد من الوقوف على النتائج لمعرفة ما إذا كانت المكتبة تطبيق الخطة التسويقية بالشكل المطلوب أم لا، وذلك من خلال رصد أرقام النتائج التي تم التوصل إليها ويمكن ذلك من خلال الإجابة عن مجموعة من الأسـئلة؛ من أهمها: 


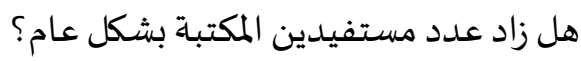

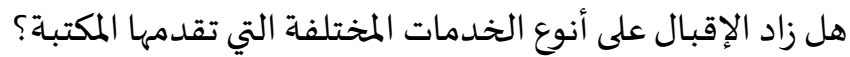

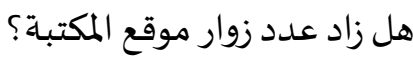

هل زاد عدد المشتركين على صفحات المكتبة بمواقع التواصل الاجتماعي المختلفة؟ موتج فإذا كانت الإجابة بـ"لا" فلابد أن هناك خطاًً ما في تنفيذ الخطة التسويقية، ويجب التحرك سريعًا لتحديد الخطأ والعمل على إصلاحه، ولا شك أن هذه الأسئلة مبنية على الأسئلة التي التي

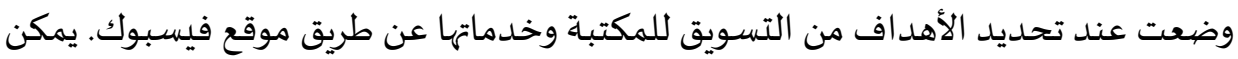

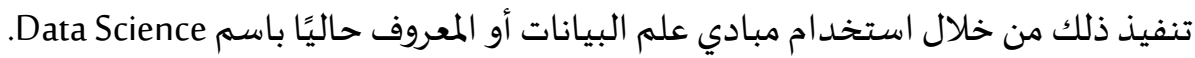

الإفادة من تطبيقات الحوسبة السحابية Cloud Computing في مجال المكتبات: .5 هي تكنولوجيا تعتمد على نقل الملفات وتوفير مساحات التخزين الخاصية بالحاسوب إلى إلى ما

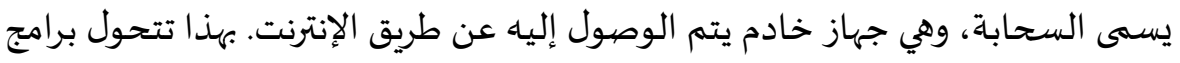

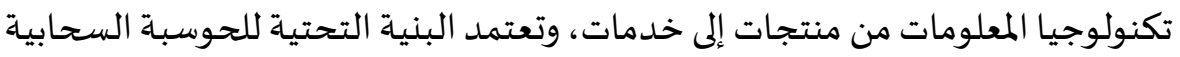

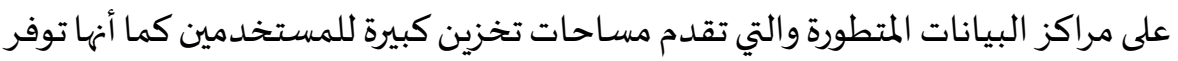

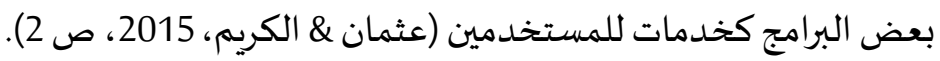
وتتمثل المتطلبات الأسـاسية للحوسبة السحابية في: أ. جهاز حاسب آلي ذو إمكانيات متوسطة، ويمكن إيصاله بشبكة الإنترنت. ب. نظام تشغيل يسمح بالاتصال بشبكة بالإنترنت. ج. متصفح لمواقع شبكة الإنترنت.

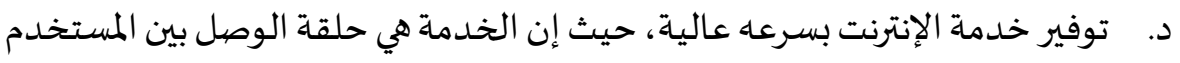
وبين كل بياناته وكل البرامج التي يستخدمها.

كما أن من أبرز نماذج الخدمة للحوسبة السحابية Services Models: أ. تقديم البرمجيات كخدمة: والتي تهتم أكثر بالتطبيقات المتعلقة بالمستخدم الههائي.

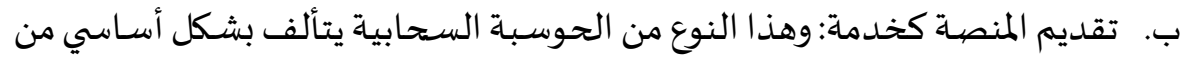
مجموعة برامج وسيطة، وتحديثات وأدوات يحتاجها مطوري البرمجيات. 


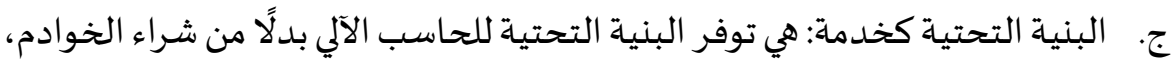

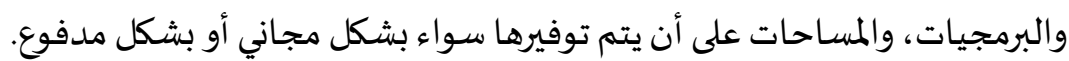

والنموذج الثالث هو الأصلح والأقرب بالطبع لاستخدامه في المرحلة الثالثة المعنية

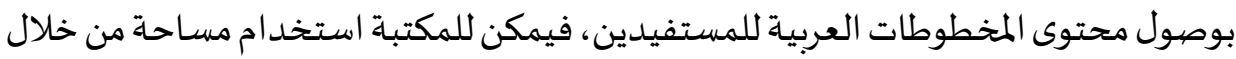

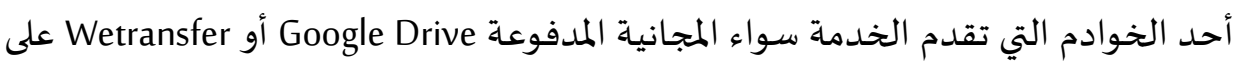
سبيل المثال؛ وذلك من أجل إرسال صفحات المخطوطات المصيورة، والتي -في معظم الأحيانتتجاوز إمكانيات التحميل الصاعد Upload المتوافر من خلال البريد الإلكتروني.

\section{5/6 المرحلة الختامية:}

يتصور بعض فرق العمل وبعض المسئولين - فيما يخص النشر الإلكتروني

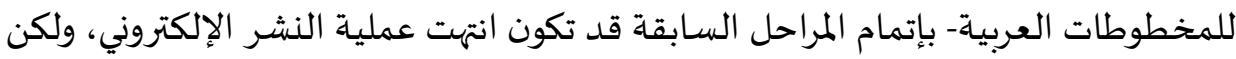

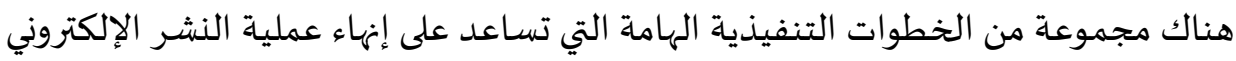

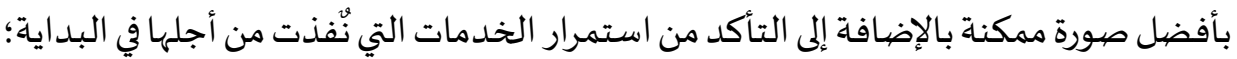

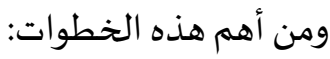

1. مراجعة أهداف عملية النشر الإلكتروني ومقارنتها بما تم إنجازه. 2. مراجعة المحتوى العلمي قبل النشر. (الصور والبيانات الوصفية للمخطوطات العربية)

3. اختبار الموقع الإلكتروني من حيث التشغيل، والحماية من القرصنة.

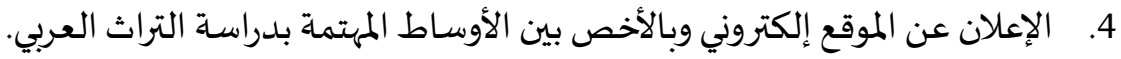
5. توثيق خطوات المشروع لتكن بمثابة دروس مستفادة لمشروعات مثيلة مستقبلًا. 6. قياس استخدام الموقع الإلكتروني من حيث التصفئ والتحميل.

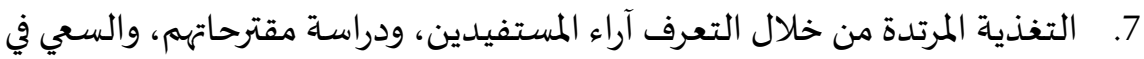
تطبيقها. 
7. - مقومات نجاح الدليل الاسترشادي:

1 . المقومات التشريعية:

من أهم المقومات التشريعية لإنجاح هذا الدليل عرضهاه على اللجنة الدائمة من الخبراء

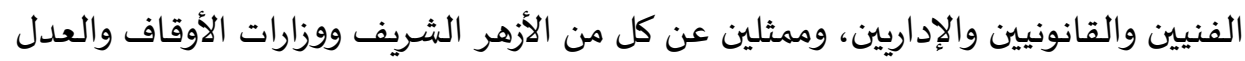

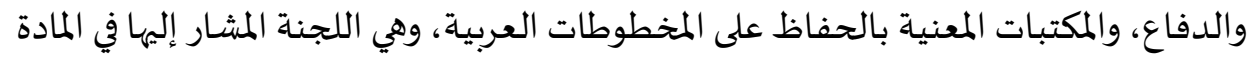
الثالثة من القانون رقم 183 لسنة 2018 الخاص بتعديل بعض ألمكام المات القانون رقم 8 لسنة المانة

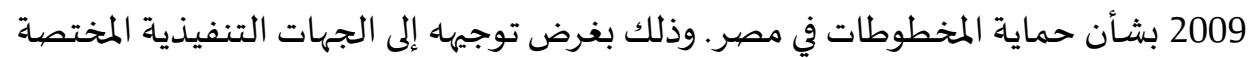

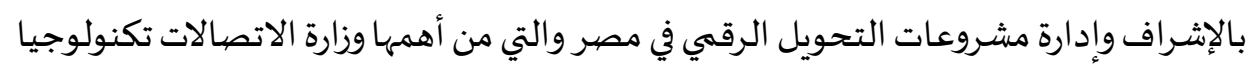
المعلومات.

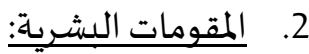

لا شك أن المقومات البشرية ترتبط بشكل مباشر بالأهداف الأساسية لعملية النشر

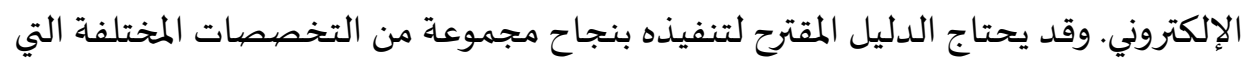

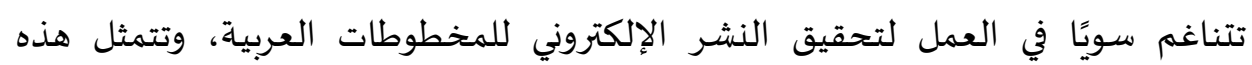
التخصصيات في تخصصات تقنية؛ وهي: تطوير البرمجيات، وتطوير قواعد البيانات، وتصهيم

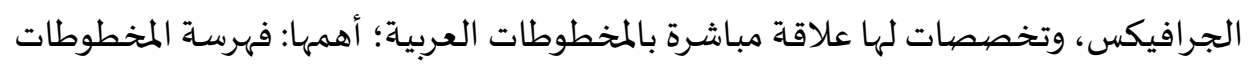
العربية، وتحقيق النصوص التراثية، والكوديكولوجيا.

\section{3. المقومات الفنية:}

تتمثل المقومات الفنية لتحقيق عناصر هذا المقترح في مجموعاة من الأجهزة والمعدات

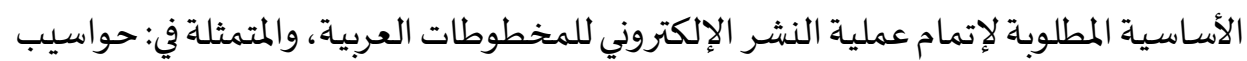

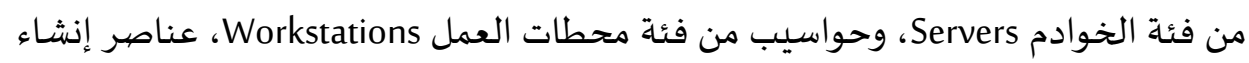
شبكة داخلية (أسلاك، موزع Switch... إلخ)، وسائط تخزين خارجية External Hard Drives.

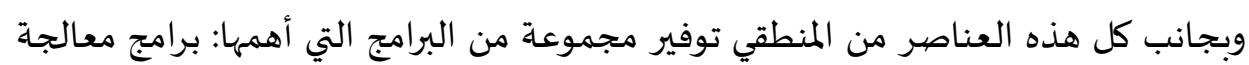

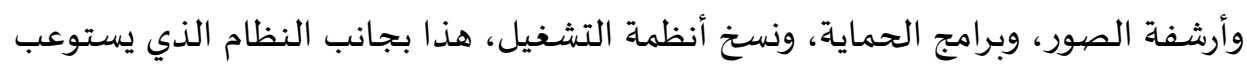
بيانات فهرسة المخطوطات العربية. 


\section{4. - المقومات المالية:}

إن توفير الميزانية من أهم مقومات تنفيذ هذا الدليل، وما لا يقل أهمية عن الميزانية هو تحديد بنود صرف هذه الميزانية؛ وتتمثل أهم هذه البنود في: بند رواتب العاملين، وبند

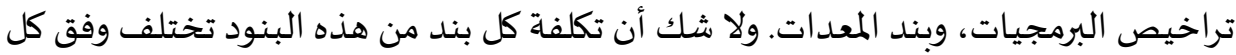
مجال تغطية لعملية النشر الإلكتروني للمخطوطات العردية العربية.

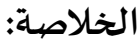

حاول الباحث في العرض السابق رصد العناصر الأساسية التي تمثل بناء مقترح للنشر الإلكتروني للمخطوطات العربية، والتي تمثلت في مجموعة من المراحل المتتالية والمتمثلة في:

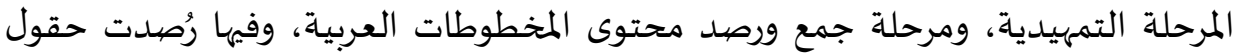

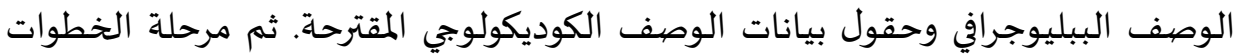

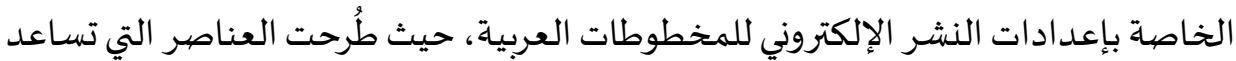

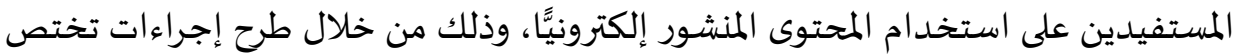

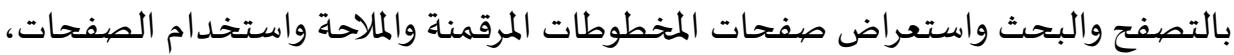
وغير ذلك من الإجراءات المعنية بتيسير استخدام هذا المحتوى عبر المواقع الإلكترونية. ثم مرحلة الإجراءات الخاصة بكيفية وصول المستفيدين لموقع المخطوطات العربة العربية من خلال شبكة الإنترنت، وذلك لمساعدة المستخدمين عند قيامهه بعملية البحث والاسترجاع من خلاع خلال محركات البحث، فضلًا عن عرض بعض النقاط التي تشير إلى كيفية الاستفادة من التسويق

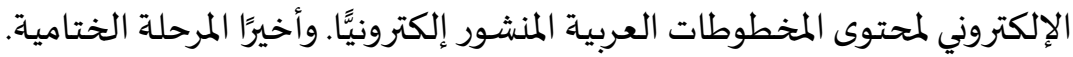




\section{المراجع}

\section{أولًا: المراجع العربية:}

النشـار، السيد السيد. (2000). النشر الإلكتروني، الإسكندرية: دار الثقافة.

الاتحاد العربي للمكتبـات والمعلومات (اعلم). (2013). قاعسدة بيانات الهادي. تاريخ الاطلاع 7 https://bit.ly/2MbNmQk يناير 2018، متاح على بدر، أحمد نور. (1996). علم المكتبات والمعلومات: دراسات في النظرية والارتباطات الموضيوعية.

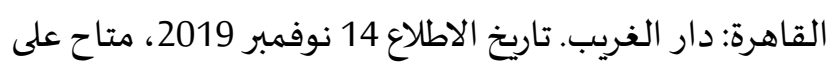

https://archive.org/details/sofi_ano_yahoo_20171228/page/n317/mode/2up

$$
\text { بنك المعرفة المصري. (د.ت). تاريخ الاطلاع } 22 \text { يناير 2017، متاح على }
$$

https://www.ekb.eg/web/guest/resources

حافظ، أحمد يوسـف. (2013). النشـر الإلكتروني ومشسروعات المكتبة الرقمية العالمية والدور

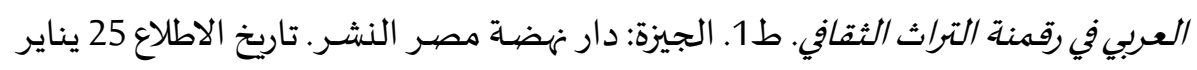

2019، متاح على https://ia801503.us.archive.org/2/items/85166/851.pdf

الحفيان، فيصـل. (2016). آمال وآلام المخطوط العربي... قيم الثقافة وثقافة القيم. المنظمة العربية للتربية والثقافة والعلوم. تاريخ الاطلاع 10 أكتوبر 2020، 2020، متاح على لكالى

https://islamonline.net/16057

$$
\text { الحلوجي، عبد الستار. (2004). نحو علم مخطوطات عربي. القاهرة: دار القاهرة. }
$$

عبد الهادي، محمد فتحي. (1999). التراث العـربي الإسـلامي: ببليوجرافيـة بالإنستـــاج الفكري

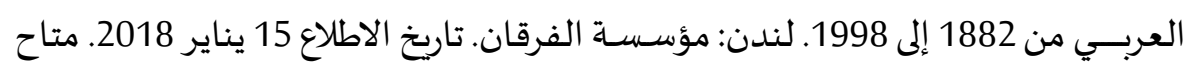
http://wadod.net/library/42/4269.pdf على 
عبــ الهـادي، محمـــ فتحي. (2009). التراث المخطوط: ببليوجرافيـة الإنتـاج الفكري العربي.

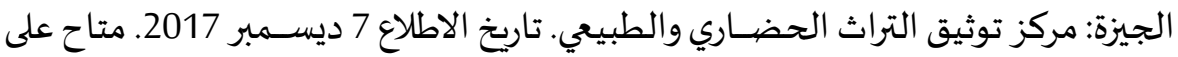
http://www.memoryarabworld.net/Doc/manuscripts\%20dalil.pdf عبد الهادي، محمد فتحي. (2010). الإنتاج الفكري العربي في مجال المكتبات والمعلومات 2005-

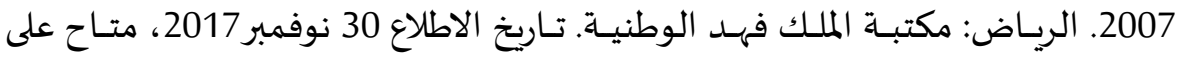
https://bit.ly/30cuYt0 عثمان، لمياء محمد \& الكريم، عبدالله عوض. (مارس 2015). الإفادة من تطبيقات الحوســبة السحابية في مجال المكتبات. في المؤتمر والمعرض السنوي عندي 21 لجمعية المكتبات المتخصصصية

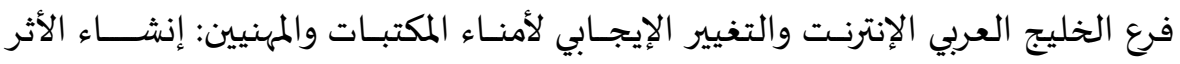

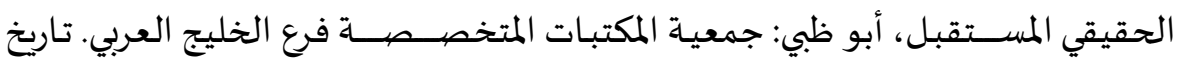

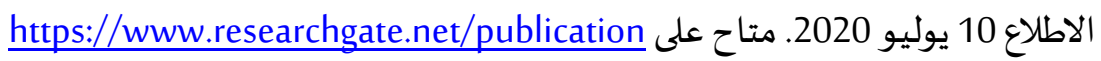
محمـد فتحي عبد الهادي. (2010). مكنز رؤوس الموضهـوعات للمخطوطات العببية. القـاهرة:

$$
\text { معهد المخطوطات العربية. }
$$

الهوش، أبو بكر محمود. (2001). التحـول من النشـر التقليدي إلى النشـر الإلكتروني. في المؤتمر

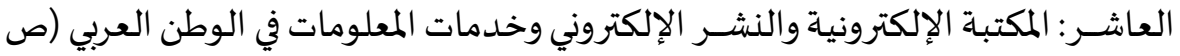

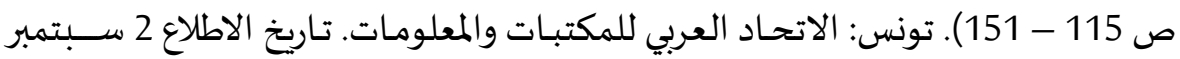

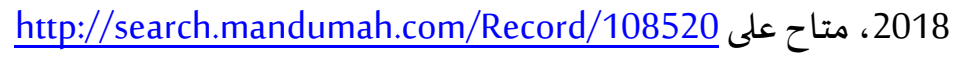

ثانيًا: المراجع الأجنـيـة:

Academia. (n.d). Accessed 8 March 2019. Retrieved from

$\underline{\text { https://www.academia.edu/ }}$

Alexa. (n.d.). The top 500 sites on the web. Accessed 5 July 2020. Retrieved from https://www.alexa.com/topsites

Algerian scientific journal platform. (n.d). Retrieved from 
النشر الإليكترونى للمخطوطات العببية : محاولة لوضع دليل عمل استرشادي

$\underline{\text { https://www.asjp.cerist.dz/ }}$

Bacher, Rahel \& Claudia, Fabian \& Ikas, Valentin (2011). EUROPEANA REGIA CIPICT- PSP 2009 - 250560: D5.3 Quality Management. Accessed 26 December 2020, $\quad$ Retrieved from

https://www.scribd.com/document/457341675/europeana-regia-

digitization-quality-management

Cybrarians Journal. (2005). Accessed 8 March 2019. Retrieved from

http://www.journal.cybrarians.info/

Federal Agencies Digitization Guidelines Initiative (FADGI). (2009). Digitization Activities: Project Planning and Management Outline. USA: Federal Agencies Digitization Guidelines Initiative. Accessed 26 December 2020, Retrieved from http://www.digitizationguidelines.gov/guidelines/digitizeplanning.html

IFLA. (2003). Guide lines for Digitization Projects for Collections and Holdings in the Public Domain, Particularly those Held by libraries And Archives. IFLA. Accessed 26 December 2020, Retrieved from https://www.ifla.org/files/assets/preservation-andconservation/publications/digitization-projects-guidelines.pdf

IFLA. (2014). Guidelines for Planning the Digitization of Rare Book and Manuscript Collections. IFLA. Accessed 26 December 2020, Retrieved from

https://www.ifla.org/files/assets/rare-books-and-manuscripts/rbmsguidelines/guidelines-for-planning-digitization.pdf

Miller, Robert. (2020). Social Media Marketing Mastery 2020:3 BOOKS IN 1. Accessed 5July 2020. Retrieved from 
https://www.amazon.com/reader/B0875Z3M2R?_encoding=UTF8\&page=13\&ret urnFromLogin=1

Reitz, J. M (n.d). ODLIS: Online Dictionary for Library and Information Science. Reverted 3 March, 2016 from

http://www.abcclio.com/ODLIS/odlis_m.aspx\#manuscript

Researchgate. (2008). Accessed 8 March 2019. Retrieved from

https://www.researchgate.net/

Schreibman, Susan \& Carignan, Yvonne \& University of Maryland. Office of Digital Collections and Research. (2007). Best practice guidelines for digital collections: at University of Maryland Libraries (2nd ed). Office of Digital Collections and Research, University of Maryland, College Park, Md. Accessed 26 December 2018,

Retrieved

from

http://ourdigitalworld.org/wpcontent/uploads/2012/04/DigitizationBestPrac tices_Schreibman.pdf 